\title{
Un registre carcéral de la Fusțāt abbasside
}

\author{
Mathieu Tillier \& Naïm Vanthieghem
}

\begin{abstract}
Résumé : Cet article propose l'édition de trois fragments d'un registre carcéral de Fusțâț conservés dans la collection Michaelidès de la Bibliothèque universitaire de Cambridge. Ils enregistrent l'arrivée de pétitions de détenus, principalement incarcérés pour dette, et mentionnent leur élargissement. Ces extraits offrent des informations capitales sur le fonctionnement des prisons au premier âge abbasside. Ils témoignent de la fréquence des incarcérations pour dette et confirment que le système carcéral s'articulait autour de la judicature cadiale et de la police (šurța), qui possédait un service administratif où étaient examinées les pétitions des détenus. Ces documents permettent ainsi de mieux comprendre le processus d'incarcération et de libération des débiteurs.
\end{abstract}

Mots-clés : Abbassides ; Égypte ; Fustāạt ; papyrus ; prison ; cadi ; police ; pétition.

\begin{abstract}
This article presents the edition of three fragments of a prison register from Fusțāt, preserved in the Michaelides Collection of the Cambridge University Library. They record the arrival of petitions from prisoners, mainly imprisoned for debt, and mention their release. These excerpts provide crucial information on the organization of prisons during the early Abbasid period. They testify to the high frequency of imprisonment for debt, and confirm that the prison system revolved around the qadi's judgeship and the police (shurta), which included an administrative service where the petitions of the detainees were examined. Thus, these documents shed new light on the process of incarceration and release of debtors.
\end{abstract}

Keywords: Abbasids; Egypt; Fusțāț; papyri; prison; qadi; police; petition.

\section{INTRODUCTION}

Les trois pages du registre que nous éditons ici ont été décrites par G. Khan dans son Catalogue of the Arabic Papyri in the Michaelides Collection. Ce dernier y avait reconnu un registre de pétitions, qu'il datait du $\mathrm{III}^{\mathrm{e}} / \mathrm{IX}^{\mathrm{e}}$ siècle ${ }^{1}$. Il s'agit de fait d'un répertoire de pétitions

\footnotetext{
* Les auteurs remercient Lahcen Daaiff pour sa relecture critique de cet article et ses corrections. Les papyrus publiés sont cités suivant les règles de la Checklist de papyrologie arabe (http://www.naherosten.lmu.de/isapchecklist).

${ }^{1}$ Ce catalogue est accessible via l'URL http://www.lib.cam.ac.uk/deptserv/neareastern/michaelides.html. G. Khan notait à propos de P. Cambr. UL Inv. Michael. A 156 : «List recording petitions. Four entries are extant and the beginning of a fifth. Each entry is headed by the phrase خلي لصاحبه 'allow to its (i.e. the petitions') owner'. The body of the entry opens with the word قصة 'petition' followed by the name of the sender, then the summary of its content». Il écrit à propos de P. Cambr. UL Inv. Michael. A 1000 : «Administrative list recording content of various petitions. Each entry opens with the 'petition of + personal name' (... قصة). » Et à propos de P. Cambr. UL Inv. Michael. B 515 : «Administrative document containing a list recording various legal acknowledgements (iqrārāt) concerning financial matters. This document is probably an official register of acknowledgements. There
} 
écrites par des personnes emprisonnées, principalement pour des dettes dont elles ne se sont pas acquittées. Ces pages, qui se présentent sous un format proche sans être parfaitement identique, ont selon toute vraisemblance été rédigées par une même personne. On n'y relève aucune perforation ou autre indice qui laisserait penser qu'elles étaient à l'origine attachées ou reliées d'une quelconque manière. Peut-être étaient-elles conservées et archivées dans une reliure à rabat comme celles qu'affectionnaient les Égyptiens ${ }^{2}$. L'écriture présente un aspect un peu anguleux sans être dépourvue d'une certaine rondeur, caractéristique que l'on rencontre dans les écritures de la seconde moitié du VIII ${ }^{\mathrm{e}}$ et de la première moitié du $\mathrm{IX}^{\mathrm{e}}$ siècle $^{3}$ : le alif descend sous la ligne, la partie inférieure de la lettre tournant dans certains cas légèrement vers la gauche ; le $b \bar{a}^{\prime}$, le $t \bar{a}^{\prime}$ et le $\underline{t} \bar{a}^{\prime}$ 'sont tantôt courts, tantôt élevés au point d'être confondus avec des $q \bar{a} f$-s, des $f \bar{a}^{\prime}$-s voire des $l \bar{a} m$-s ; les lettres ğ $\bar{\imath} m, h \bar{a}^{\prime}$ et $h \bar{a}^{\prime}$ adoptent soit un angle de $45^{\circ}$, soit une forme ronde tel un $s \bar{a} d$ ou un $\frac{d}{\bar{a}} \bar{d}$; le $d \bar{a} l$ est tracé en croissant de lune, singulièrement quand il est en position initiale, ou sous la forme d'un trait oblique qui se confond avec un $r \bar{a}$ ' ou un $z \bar{a} y$; le $\sin$ et le $\sin$ sont pourvus de trois petites dents ou réduits à un simple trait horizontal long; quant au 'ayn final, il s'achève par un retour vers la droite. Le texte est dépourvu de points diacritiques; le sinn est régulièrement surmonté d'un trait horizontal qui permet de le distinguer de son homographe šìn ${ }^{4}$.

Ces pages contiennent une série de dix-huit vignettes ou paragraphes qui consistent en quelques lignes d'arabe précédées de la mention hulliya(t) (lit. «il/elle a été libéré(e)») ou hulliya li-ṣăhibi-hi (lit. «il a été libéré pour son adversaire ») - écrite au moyen d'un calame épais ${ }^{5}$, et encadrées dans le coin supérieur droit d'un trait. Chaque paragraphe présente, sauf dans un cas $\left(\mathrm{n}^{\circ} 7\right)$, un formulaire similaire. Les vignettes sont introduites par le mot qișsa («pétition ») suivi du nom du débiteur emprisonné. Le montant de la dette qui lui a valu sa mise sous écrou est ensuite introduit par les mots fí dayn («à propos d'une dette ») ou par la seule préposition $f \grave{l}$ («à propos de ») suivi d'un montant. On lit ensuite la formule aqarra bi-hā («qu'il a avouée ») suivie du nom du créancier, introduite par la préposition $l i$ - (« en faveur de »), par laquelle le scribe indique que le débiteur a reconnu devoir le montant mentionné. Il donne l'adresse du créancier, le plus souvent sous forme tripartite, en commençant par le nom du quartier, puis en indiquant un point de repère notoire, et enfin la maison, désignée soit par

are three entries on the recto. Each entry opens with a siglum (the meaning of which is unclear) followed by لصناحبه. The text of the entry opens with the word قصة followed by a person name, i.e. 'the affair of so-and-so'. The entry summarizes the content of the 'iqrär. (On the verso) continuation of the text on the recto. There are two entries on the verso. One of these is relatively long (10 lines) and opens: قصة محمد بن مكرم 》.

${ }^{2}$ Sur les reliures de ce type, voir F. Déroche, Manuel de codicologie des manuscrits en écriture arabe, Bibliothèque nationale de France, Paris, 2000, p. 309-326. C'est ce type de reliure qui a été utilisé pour protéger le manuscrit du Ğāmi ' d'Ibn Wahb (J. David-Weill, Le Djâmi ' d'Ibn Wahb, Institut français d'archéologie orientale, Le Caire, 1939-1948, I, p. i) ou encore pour conserver le codex fiscal P. Lond. IV 1419. Une image de cette reliure est disponible en haute définition à l'URL http://www.bl.uk/manuscripts/Viewer.aspx?ref=papyrus_1442_fblefv (nous devons cette information à Arietta Papaconstantinou, que nous remercions chaleureusement).

${ }^{3}$ L'écriture peut être comparée à celle de $P$. Diem Fruehe Urkunden 6-7, de $P$. Khalili I 10 ainsi que de l'inédit P. Louvre Inv. JDW 97.

${ }^{4}$ À propos de ce type d'écriture cursive, voir G. Khan, Arabic Papyri. Selected Material from the Khalili Collection, The Nour Foundation, Londres, 1992, p. 39-43.

${ }^{5}$ Nous rendons cette épaisseur de trait par des grasses dans l'édition. 
le nom de son propriétaire présent ou passé, soit sous la forme d'un lieu-dit. Chaque paragraphe se clôt par une date réduite à un simple quantième et à un mois. Les parties sont identifiées dans le registre par leur nom et, souvent - mais pas systématiquement -, par un patronyme, parfois suivi de leur profession ou, ce qui est plutôt rare dans la documentation arabe, par un trait physique qui leur servait peut-être de surnom (̌̌ $u h r a)^{6}$.

Toutes les vignettes de notre registre sont datées des mois de șafar et de rabī' I d'une année qui n'est pas mentionnée. Comme le cas $\mathrm{n}^{\mathrm{0}} \mathbf{7}$ mentionne probablement le gouverneur 'Abd Allāh b. Muhammad, en poste du 18 ša 'bān 189 au 19 ša 'bān 190 (soit du 20 juillet 805 au 10 juillet 806), notre document doit avoir été écrit en șafar de l'année 190 (janvier 806). Les toponymes qui y sont mentionnés montrent par ailleurs qu'il provient de Fusțâț, comme de nombreuses pièces de l'ancienne collection G. Michaelidès ${ }^{7}$, et plus particulièrement des quartiers centraux de la ville, où ont vraisemblablement été mises au jour au moins deux autres pièces de cette collection ${ }^{8}$.

\section{1. ÉDITIONS}

Coupon de papyrus de couleur brun clair. La marge supérieure ainsi que les marges de gauche et de droite sont conservées ; le document est endommagé en bas et l'ampleur des pertes est difficile à préciser. Le texte comporte quatre paragraphes complets ainsi que le début d'un cinquième, le tout étant réparti sur trente-et-une lignes. Le texte a été écrit au dos d'une ancienne lettre, inédite, dont on conserve l'extrémité gauche.

P. Cambr. CUL Inv. Michael. A 156 verso

Fusțāt $34 \times 10,5 \mathrm{~cm}$ (Fig. 1) șafar 190/janvier 806 (?)

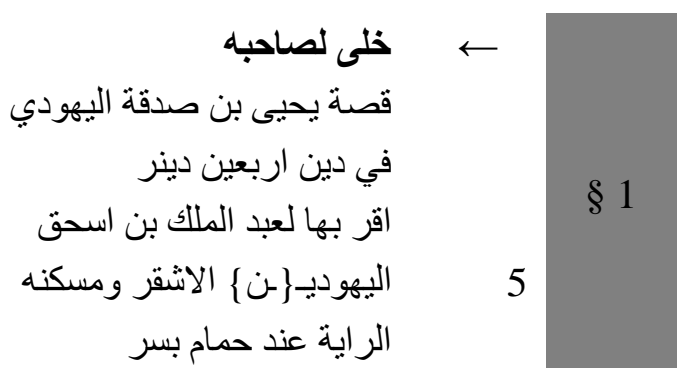

\footnotetext{
${ }^{6}$ On trouve ainsi un « roux $»\left(n^{\circ} \mathbf{1}\right)$, un « noir », $\left(n^{\circ} \mathbf{2}\right)$ et un « bigleux $»\left(n^{\circ} \mathbf{1 2}\right)$.

${ }^{7}$ Cf. la lettre inédite P. Cambr. UL Inv. Michael. A 28 qui indique qu'elle devait être remise à Fusțāṭ (yudfa 'bi-lFustāt) ainsi que P. Cambr. UL Inv. Michael. A 1041 ; sur cette dernière lettre, cf. Kh. Younes, Joy and Sorrow in Early Muslim Egypt. Arabic Papyrus Letters. Text and Content, thèse de doctorat, Université de Leyde, 2013, p. 171-176, $\mathrm{n}^{\mathrm{o}}$ 23. Sur l'acquisition de la collection Michaelidès, voir S. J. Clackson, « The Michaelides Manuscript Collection », Zeitschrit für Papyrologie und Epigraphik, 100 (1994), p. 223-226.

${ }^{8}$ Le formulaire inédit de reçu de taxe P. Cambr. UL Inv. Michael. B 12, 1, mentionne un agent de la ville haute de Fusțāt ( 'āmil a 'lā Fusțât) et le contrat de location inédit P. Cambr. UL Inv. Michael. B 327, 3-4 signale une maison

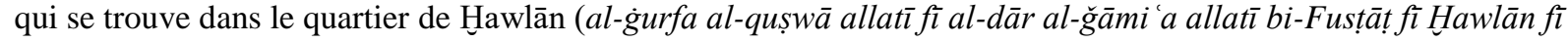
| maḥras Rāmiğa 'alā al-h̆ațt al-a żam).
} 


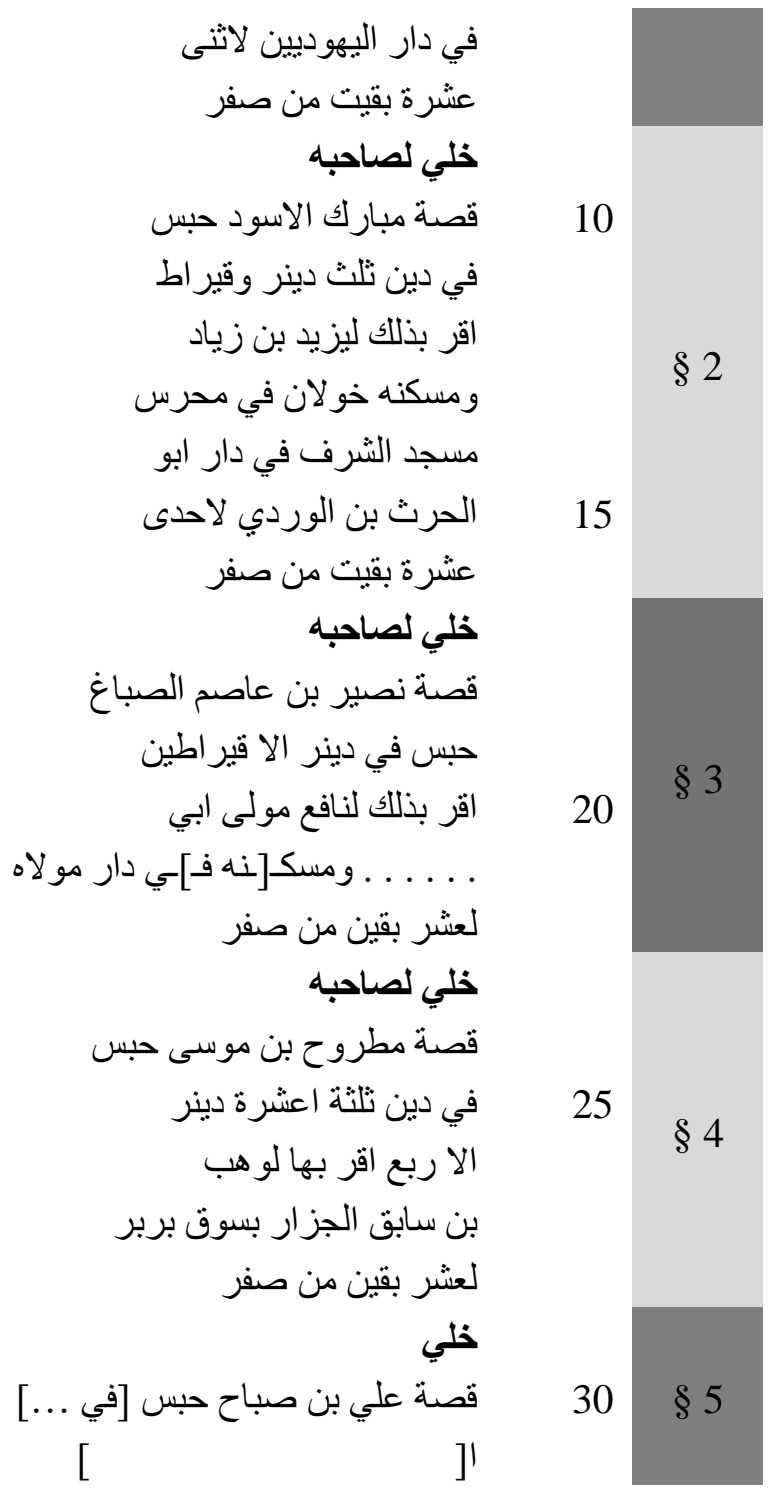

13 مستكنه pap.

«[§ 1] Libéré pour son adversaire. Pétition de Yahyā b. Șadaqa le Juif concernant une dette de quarante dinars qu'il a avouée en faveur de 'Abd al-Malik b. Isḥāq $\left.\right|^{5}$ le Juif roux, résidant à alRāya, près du hammam Busr, dans la maison des juifs. Douze jours restant de șafar.

[§ 2] Libéré pour son adversaire. $\mid{ }^{10}$ Pétition de Mubārak le Noir, emprisonné pour une dette de trois dinars et un qīrāt qu'il a avouée en faveur de Yazīd b. Ziyād, résidant à Hawlān, dans la caserne de la mosquée al-Šaraf, dans la maison $\left.\right|^{15}$ d'al-Hārit b. al-Wardī. Onze jours restant de safar.

[§ 3] Libéré pour son adversaire. Pétition de Nuṣayr b. 'Āṣim le Teinturier, emprisonné pour un dinar moins deux qīrāt-s $\left.\right|^{20}$ qu'il a avoué devoir à Nāfi', le client d'Abū ..., résidant dans la maison de son patron. Dix jours restant de șafar.

[§ 4] Libéré pour son adversaire. Pétition de Mațrūh b. Mūsā, emprisonné $\left.\right|^{25}$ pour une dette de treize dinars moins un quart qu'il a avouée en faveur de Wahb b. Sābiq le boucher au souk Barbar. Dix jours restant de șafar. 
[§ 5] Libéré. ${ }^{\beta 0}$ Pétition de 'Alī b. Șabāḥ, emprisonné pour ... »

4-5 li- 'Abd al-Malik b. Is hăq $\|$ al-yahūday $\{\boldsymbol{n}\}$ On peut interpréter la séquence de deux manières. Soit l'ethnique al-yahüdī se rapporte à 'Abd al-Malik uniquement, auquel cas il n'y a aucune raison de le décliner au duel, soit il est appliqué volontairement par le scribe au fils et au père pour préciser que tous deux sont juifs et le duel s'impose. La seconde hypothèse pourrait s'expliquer par le fait que le nom 'Abd al-Malik n'est pas en arabe un nom typique de l'onomastique juive.

6 hammām Busr Ce bain situé à proximité de la grande mosquée de 'Amr est mentionné par Ibn 'Abd al-Hakam, Futūh Mișr, p. 112. Il tire son nom du Compagnon Busr b. Abī Arțāt al-Qurašī al- 'Āmirī, qui prit part à la conquête de l'Égypte et s'installa à Fusțâtt. Il fut notamment amiral de la flotte de Mu'āwiya. Voir Ibn Yūnus, Ta'rīhn, I, p. 62-63 ; I. Hasson, « Busr b. Abī Artật », $E I^{3}$, s.v.

13-14 mahras masğid al-Šaraf Le scribe semble avoir écrit dans un premier temps محس, avant de se reprendre et d'écrire محرس. Sur ce terme, voir plus bas les commentaires du document II, 1. 5. Dans le cas du masğid, il a écrit מحد, traçant le ğìm de manière anticipée avant même d'avoir pleinement réalisé le $\sin$; voyant sa faute, il a ensuite tenté de reprendre le cours de la lettre $\sin$ dans son ğìm et a noté un nouveau ǧìm suivi d'un dāl. Le toponyme alŠaraf désigne une plaine à l'est de la forteresse de Babylone. Voir P. Casanova, Essai de reconstitution topographique de la ville d'al Fousțât ou Mișr, Institut français d'archéologie orientale, Le Caire, 1919, III, p.

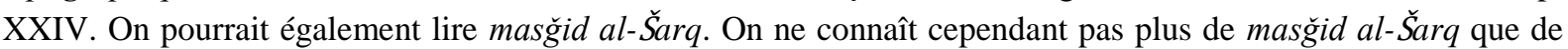
masğid al-Šaraf à Fusțāṭ.

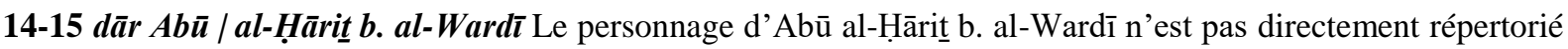
par les sources ; il serait néanmoins tentant de l'identifier avec un membre de la famille d'Abū Bakr Muhammad b. al-Hārit b. 'Abd al-Ḥamīd b. 'Amr b. Ḩālid b. Rāšid al-Hูawlānī al-Miṣrī (m. 289/902), traditionniste et mawlā de Hawlān, surnommé Ibn al-Wardī, par exemple son grand-père ; sur ce personnage, voir Ibn Yūnus, Ta'rīh , I, p. 440.

20 li-Năfi ' mawlä Abī ... | wa-mas[kanu-hu flā dār mawlä-hu Il est intéressant de constater que le mawlā Nāfi', le créancier, habitait chez son «patron », ce qui témoigne de l'intégration durable des esclaves affranchis dans la maison de leur ancien maitre.

25 fĩ dayn talätat a šara Sur l'alif prosthétique placé devant le 'ayn de 'ašar, cf. S. Hopkins, Studies in the Grammar of Early Arabic. Based upon Papyri Datable to Before 300 A.H./912 A.D., Oxford University Press, Oxford, 1984, p. 114-115, § 95b.

27 bi-sūq Barbar Ce marché bien connu par les sources arabes se trouvait à l'angle du darb al-Qasțallānī et du zuqāq al-Qanādīl ; voir P. Casanova, Essai de reconstitution topographique, p. 46-47. Le même toponyme apparaît dans le document III, 14.

30 'Alī b. Ṣabāh On pourrait lire aussi b. Șabbāḥ, b. Șayyāḥ, b. Ḍayyāḥ, ou encore b. Ṣannāğ. Voir al-Ḍahabī, alMuštabih fì asmā' al-riğăl, éd. P. de Jong, Brill, Leyde, 1881, p. 309-310.

Coupon de papyrus de couleur brun clair écrit au recto et au verso. La marge supérieure ainsi que les marges de gauche et de droite sont conservées ; le document est endommagé en bas et l'ampleur des pertes est difficile à préciser. Le texte comporte quatre paragraphes complets ainsi que le début de deux autres, le tout étant réparti sur quarante-deux lignes.

\section{RECTO}

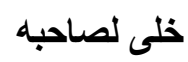




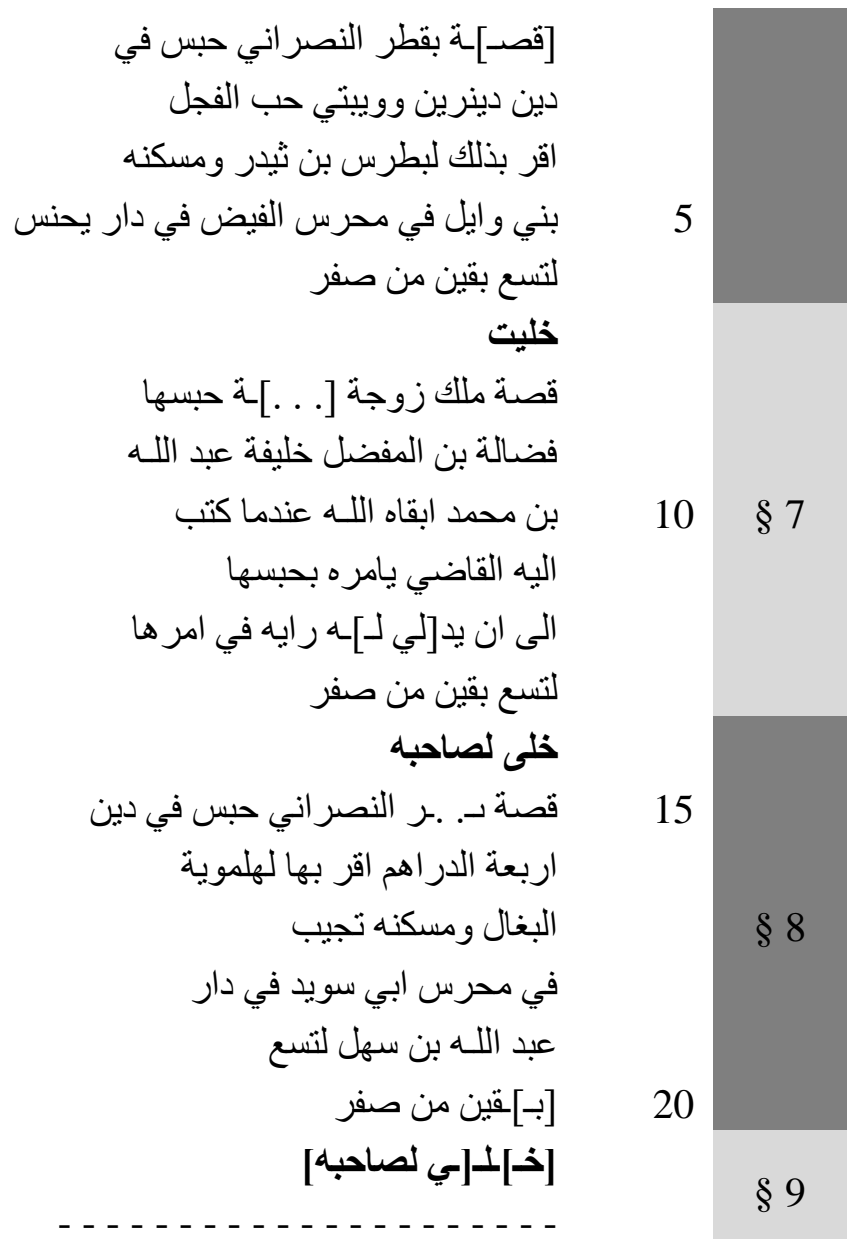

\section{VERSO}

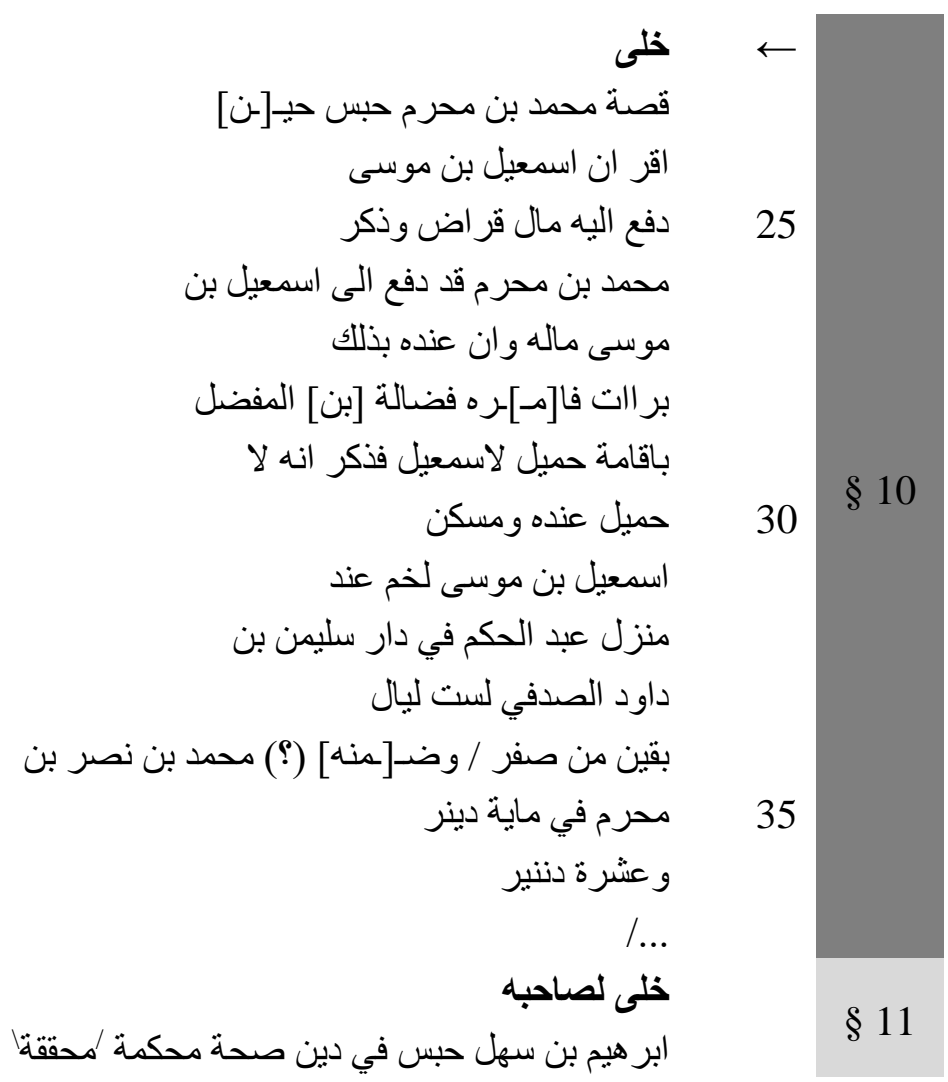




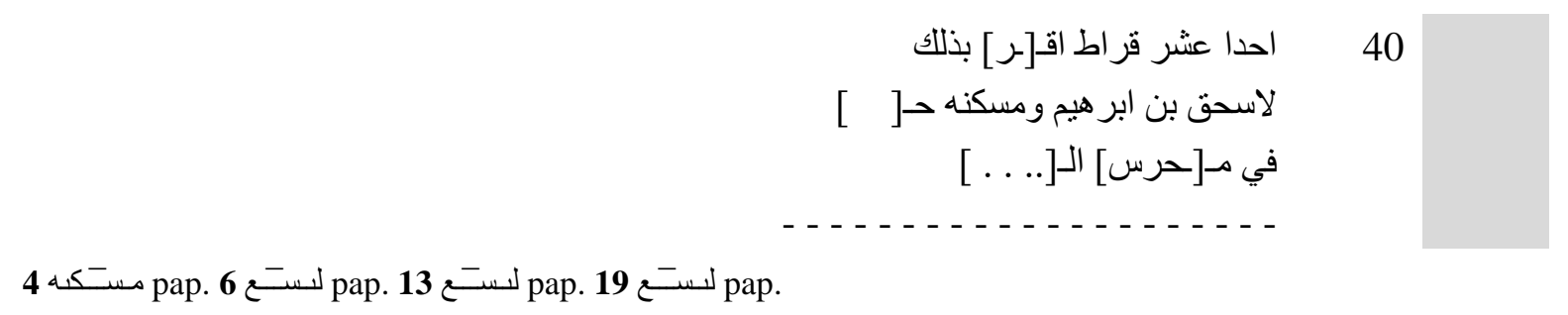

«(Recto) [§ 6] Libéré pour son adversaire. Pétition de Biqțur le Chrétien, emprisonné pour une dette de deux dinars et deux wayba-s de semences de radis, qu'il a avouée en faveur de Buṭus b. Tiyudur, résidant $\left.\right|^{5}$ à Banū Wā'il, près de la caserne de l'Abondance, dans la maison de Yuhannis. Neuf jours restant de șafar.

[§ 7] Libérée. Pétition de Malak, épouse de [...]a, que Faḍāla b. al-Mufaḍḍal, vicaire de 'Abd Allāh $\mid{ }^{10}$ b. Muḥammad - que Dieu prolonge son existence ! - a emprisonnée lorsque le cadi lui a écrit, lui ordonnant de l'emprisonner jusqu'à ce qu'il lui fasse parvenir sa décision la concernant. Neuf jours restant de șafar.

[§ 8] Libéré pour son adversaire. $\left.\right|^{15}$ Pétition de B...r le Chrétien, emprisonné pour une dette de quatre dirhams qu'il a avouée en faveur de Halmūya le Muletier, résidant à Tuğīb près de la caserne Abū Suwayd, dans la maison de 'Abd Allāh b. Sahl. Neuf jours ${ }^{20}$ [re]stant de șafar.

[§ 9] [Li]bé[ré].

(Verso) [§ 10] Libéré. Pétition de Muḥammad b. Muḥrim, emprisonné [après avoir] avoué qu'Ismā 'îl b. Mūsā $\left.\right|^{25}$ lui avait versé de l'argent sous forme de qirậ̣. Muḥammad b. Muhrim a mentionné qu'il avait rendu son argent à Ismā'̄̄l b. Mūsā, et qu'il possédait des quittances relatives à cela. Faḍāla b. al-Mufaḍdal lui a ordonné d'instituer un garant au profit d'Ismā̄ềl, et [Muḥammad] a mentionné qu'il n'avait pas $\left.\right|^{30}$ de garant à sa disposition. Ismā ‘̄il b. Mūsā réside à Laḩm, près de la demeure de 'Abd al-Hakam, dans la maison de Sulaymān b. Dā'ūd al-Ṣadafî. Six nuits restant de șafar. Muhammad b. Naṣr b. $\left.\right|^{35}$ Muhrim s'est porté garant sur la somme de cent dinars et dix dinars.

[§ 11] Libéré pour son adversaire. Ibrāhīm $\mathrm{b}$. Sahl a été emprisonné pour une dette valide, solidement établie et vérifiée $\left.\right|^{40}$ de onze qirāt-s, qu'il a avou[ée] en faveur d'Ishāā b. Ibrāhīm, habitant H.... près de la caserne .... »

3 wa-waybatay habb al-fuğl La wayba est une unité de mesure sèche dont il existe deux variantes principales en Égypte : la wayba employée dans le Fayoum, dite d'al-Sarī, du nom du gouverneur et surintendant des finances al-Sarī b. al-Ḥakam b. Yūsuf (200-201/816, puis 201-205/817-820) ; la wayba utilisée en Moyenne-Égypte dite wayba ibrāhīmiyya, qui tire son nom du gouverneur Ibrāhīm b. Șālih (164-167/781-784, puis 176/792). Une wayba équivaudrait à $1 / 6$ d'irdabb, soit 15 litres ou encore 11,6 kg de blé; sur cette mesure, voir A. Grohmann, Einführung und Chrestomathie zur arabischen Papyruskunde. I. Einführung, Státní Pedagogické Nakladatelství, Prague, 1954, p. 157-158 ; W. Hinz, Islamische Masse und Gewichte, umgerechnet ins metrische System, Brill, Leyde, 1955, p. 52, ainsi que W. Diem, Arabischer Terminkauf. Ein Beitrag zur Rechts- und Wirtschaftsgeschichte Ägyptens im 8. bis 14. Jahrhundert, Harrassowitz, Wiesbaden, 2006, p. 95-102. Si Biqțur a emprunté des graines de radis, c'est soit pour les semer, soit pour en faire de l'huile; pour une attestation d'huile de radis dans les papyrus, cf. entre autres P. Berl. Arab. II 61, 5. 
5 fì mahras al-fayḍ Le sens de mahras est incertain. Il s'agit vraisemblablement d'un bâtiment lié à l'origine aux activités militaires des membres d'une tribu. Chaque quartier tribal disposait de sa mosquée et de son mahras. Voir W. Kubiak, Al-Fustat. Its Foundation and Early Urban Development, Wydawnictwa Uniwersytetu Warszawskiego, Varsovie, 1982, p. 123 ; S. Denoix, Décrire Le Caire. Fusțăt-Mișr d'après Ibn Duqmāq et Maqrīzī, Ifao, Le Caire, 1992, p. 140. R. Dozy définit ainsi ce terme : «enceinte fermée de murs et assez grande pour loger une petite garnison », « caserne », «bâtiment destiné à loger les étudiants, les moines, les voyageurs et les pauvres », «échauguette, guérite, beffroi, tour de guet 》 (R. Dozy, Supplément aux dictionnaires arabes, Brill, Leyde, 1881, I, p. 270). Quant au mot fayḍ, il désigne «l'abondance, la crue, le débordement » et est aussi l'un des surnoms donnés au Nil (voir R. Dozy, Supplément, II, p. 302 ; E.W. Lane, An Arabic-English Lexicon, Williams and Norgate, Londres-Édimbourg, 1863-1893, VI, p. 2473).

8 Malak zawğat [. . . Ja On pourrait par exemple restituer Malak zawğat [Rif']a.

15 qișsat B...r Le nom de ce personnage doit sans doute être restitué Biqtur.

16-17 li-Halmūya |al-bag ġăl Le nom Halmūya est peut-être une transcription avec lambdacisme du nom grécoégyptien гермдү $\omega$ ou l'une de ses variantes (TM Name 34871). D'un point de vue paléographique, une lecture al-baqqāl pour la profession du créancier serait tout aussi valable, ce qui signifierait qu'il était marchand de légumes et non muletier.

23 Muhammad b. Muhrim G. Khan lisait le patronyme Mukarram, mais c'est bien le rasm محرم qu'il faut reconnaître. La vocalisation et la ponctuation diacritique du rasm sont incertaines : on pourrait aussi lire Muharram, Muhazzam, Miğzam. Voir al-Dahabī, al-Muštabih fí asmā̄' al-riğāl, p. 469.

hubisa hīi[na] On pourrait aussi lire hubisa hattā («il a été emprisonné jusqu’à ce que... »). Dans cette hypothèse, il faudrait néanmoins admettre que le débiteur a été emprisonné préventivement en l'absence de preuve, ce qui semble incompatible avec les règles de l'emprisonnement pour dette établies par le fiqh.

25 wa-d dakara On pourrait aussi lire wa-aqarra («a avoué »).

28 Faḍala [b.] al-Mufaḍal Sur ce personnage, voir nos développements plus bas.

33 al-Ṣadafĩ Les lectures al-Ṣāfĩ et al-Ṣadaqī sont possibles mais peu probables. En effet la nisba al-Șadafĩ, renvoyant à la tribu himyarite de Șadif, est très courante en Égypte à cette époque, tandis que celle d'al-Ṣadaqī (renvoyant à une rue de Marw au Hurāsān) n'est pas attestée chez Ibn Yūnus. Sur ces nisba-s, voir al-Sam ānī, alAnsāb, éd. 'Abd Allāh 'Umar al-Bārūdī, Dār al-ğanān, Beyrouth, 1988, III, p. 528, 530.

41 wa-maskanu-hu Hẹ[ ] Étant donné que le créancier habitait les quartiers centraux de Fusțāt, seules deux restitutions nous paraissent envisageables : wa-maskanu-hu H[adramawt] ou encore wa-maskanu-hu H[awlän].

\section{III}

Coupon de papyrus de couleur brun clair. Seule la marge de droite est conservée ; une partie de la marge supérieure est sans doute préservée. Les pertes à gauche sont minimes mais l'ampleur des mutilations au bas du document est difficile à préciser. On distingue six paragraphes complets ainsi que le début d'un septième, le tout étant réparti sur trente-et-une lignes. Le texte a été écrit au dos d'une ancienne pétition, inédite, dont on conserve la moitié gauche et où l'on lit entre autres les mots rafa 'tu ilā sayyidī al-amīr abqā-hu Allāh qiṣṣa (« je soumets à mon maître le gouverneur - que Dieu prolonge son existence ! - une pétition »).

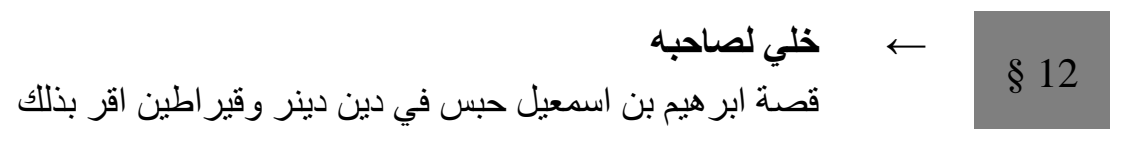




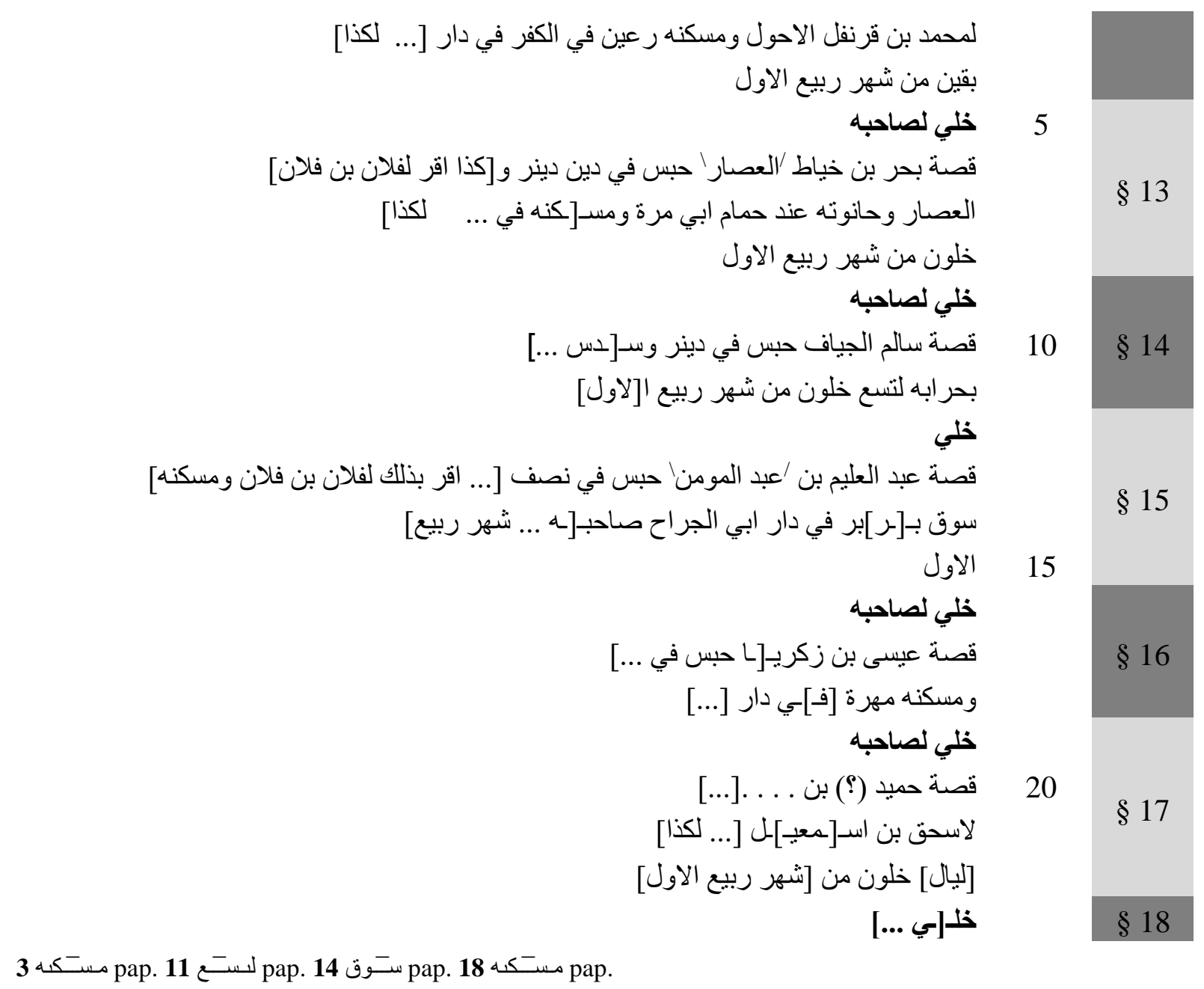

« [§ 12] Libéré pour son adversaire. Pétition d'Ibrāhīm b. Ismā̄̄il, emprisonné pour une dette d'un dinar et deux qīrāt-s qu'il a avouée en faveur de Muhammad b. Qaranful le Bigleux, résidant à Ru'ayn, dans al-Kafr (?), dans la maison de ... . [Tant de jours] restant du mois de $r a b \bar{l}^{`} \mathrm{I}$.

[§ 13] $\left.\right|^{5}$ Libéré pour son adversaire. Pétition de Baḥr b. Hुayyāṭ le Presseur, emprisonné pour une dette d'un dinar et [... qu'il a avouée en faveur d'Untel fils d'Untel] le Presseur, dont la boutique se situe près du hammam Abū Murra, et qui hab[ite ...]. [Tant de jours] passés du mois de $r a b \bar{l}^{c} \mathrm{I}$.

[§ 14] Libéré pour son adversaire. $\mid{ }^{10}$ Pétition de Sālim le Fossoyeur, emprisonné pour un dinar, un sixième... Il réside ... dans son gourbi. Neuf jours passés du mois de $r a b \imath^{\prime} I$.

[§ 15] Libéré. Pétition de 'Abd al- 'Alīm b. 'Abd al-Mu'min, emprisonné pour un demi [... en faveur d'Untel fils d'Untel, résidant] au souk Barbar, dans la maison d'Abū 1-Ğarrāh son compère. [Tant de jours passés du mois de $\left.r a b \bar{\imath}^{\dagger}\right]\left.\right|^{15} \mathrm{I}$.

[§ 16] Libéré pour son adversaire. Pétition de 'Īsā b. Zakariyā, emprisonné pour .... Il réside à Mahra, [d]ans la maison ... . 
[§ 17] Libéré pour son adversaire. ${ }^{20}$ Pétition de Ḥumayd b. ..., emprisonné pour une dette de ... qu'il a avouée en faveur de] Isḥāq b. Is[mā'î] 1 ... [Tant de nuits] passées du mois de $\operatorname{rabī} \mathrm{I}$.

[§ 18] Libéré ... »

3 li-Muhammad b. Qaranful Le patronyme dérive du mot qaranful qui désigne la «giroflée, le clou de girofle » (voir A. de B. Kazimirski, Dictionnaire arabe-français, Maisonneuve, Paris, 1860, II, p. 729 ; R. Dozy, Supplément, II, p. 340, ainsi que E. Ashtor, « Karanful », $E I^{2}$, IV, p. 651).

fĩ al-kafr La lecture est incertaine. Le mot kafr, courant dans la toponymie égyptienne, désigne un village ou un hameau (A. de B. Kazimirski, Dictionnaire, II, p. 914). On voit cependant mal à quoi cela ferait référence dans la toponymie de Fusțāṭ.

4 baqūna min šahr rabī al-awwal Les entrées suivantes portent des dates en halawna min šahr rabī al-awwal. Dans la mesure où les dates se suivent dans les feuillets précédents du registre, il est possible qu'il s'agisse d'une erreur de scribe, qui aurait écrit baqīna (« restant ») à la place de halawna («passés »).

6 Bahr b. Hayyāt al- 'așșār L'ism de ce personnage peut aussi se lire Baḥar ou Buhur ; voir al-Dahabī, al-Muštabih fi asmā' al-riğăl, p. 27. On pourrait reconnaître dans le rasm le terme al-qașșār, auquel cas Baḥr b. Hayyāt serait un blanchisseur ; pour des occurrences de blanchisseurs dans les papyrus, cf. entre autres P. Terminkauf 2, 10-11 et P. Prag. Arab. 45, II, 2.

7 hammām Abī Murra Le complexe thermal d'Abū Murra était connu à l'époque omeyyade sous le nom de « hammam de Zabbān b. 'Abd al- 'Azīz ». Il fut édifié par le gouverneur 'Abd al- Azīz b. Marwān (r. 65-86/685705) pour son fils Zabbān (m. 132/750), et abritait une célèbre statue de marbre représentant une femme à la poitrine dénudée. Celle-ci fut détruite en l'an 104/723 suite à la promulgation d'un édit iconoclaste par le calife Yazīd II (r. 101-105/720-723). Voir Ibn 'Abd al-Hakam, Futūh Miṣr, p. 113-114 ; al-Kindī, Ta'rīh Miṣr wawulāti-hā, dans Kitāb al-wulāt wa-kitāb al-quḍăt, éd. R. Guest, Brill, Leyde, 1912, p. 71-72. Cf. S. Denoix, « Des thermes aux hammams : nouveaux modèles ou recompositions ? », dans M.-F. Boussac, Th. Fournet et B. Redon (éd.), Le bain collectif en Égypte, Ifao, Le Caire, 2009, p. 22 ; Ch. Sahner, «The First Iconoclasm in Islam: A New History of the Edict of Yazīd II (AH 104/AD 723) », Der Islam, 94 (2017), p. 20-21.

11 bi-harābi-hi Harāab désigne couramment un lieu de désolation et de ruine (A. de B. Kazimirski, Dictionnaire, I, p. 552). Notons qu'al-Kindī évoque un « harāb de Ḥimyar » dans lequel se réfugia le gouverneur Ḥaf̣ b. alWalīd en 128/746, lors de la troisième fitna. Al-Kindī, Wulāt, p. 86. Il est également possible de lire bi-harāba («dans une masure/un gourbi »; voir R. Dozy, Supplément, I, p. 357).

13-14 hubisa fĩ nișf [ Il faut sans doute restituer hubisa fì nișf [dīnarr]. Immédiatement après figurait peut-être une profession, comme dans le $\S 4$ où le créancier est décrit comme boucher au souk Barbar; si tel est le cas, on pourrait proposer la restitution hubisa fì nișf [dīnār wa-huwa kad̄a fì] |sūq Barbar. L'autre solution, que nous préférons à la première, consiste à voir le souk comme le lieu où le créancier a élu domicile, auquel cas on doit restituer hubisa fì niș [dīnār li-fulān b. fulān wa-maskanu-hu] | sūq Barbar.

\section{DES AFFAIRES DE CRÉANCES}

Les parties mentionnées dans le registre ont pour la plupart été incarcérées en raison d'une somme d'argent dont elles ne voulaient pas s'acquitter, ou qu'elles ne parvenaient pas à rembourser. Ces sommes sont très souvent appelées « dettes » (dayn) $\left(\mathrm{n}^{\mathrm{os}} \mathbf{1}, \mathbf{2}, \mathbf{4}, \mathbf{6}, \mathbf{8}, \mathbf{1 1}, \mathbf{1 2}\right.$, 13), ce qui suggère qu'il s'agit de prêts contractés auprès d'un créancier. Dans certains cas, cependant, la somme à payer n'est pas qualifiée ainsi $\left(n^{\text {os }} \mathbf{3}, \mathbf{1 4}, \mathbf{1 5}\right)$; elle pourrait être due à un 
autre titre, et correspondre au prix d'une location ou d'un achat ${ }^{9}$. Dans la mesure où il s'agit aussi d'une forme de créance, nous rassemblons les deux catégories dans l'analyse qui suit. La plupart des prêts adoptent une forme classique, à savoir que le débiteur doit s'acquitter de la totalité de la somme mentionnée. Dans un cas, néanmoins, la dette prend la forme particulière du qirăd $\left(\mathrm{n}^{\mathrm{0}} \mathbf{1 0}\right)$, un type de prêt qui était contracté auprès d'un investisseur. Au terme du contrat, le débiteur devait restituer au créancier le capital et lui verser une partie des bénéfices ; en cas d'insuccès de l'investissement, le débiteur n'était pas tenu de rembourser le capital ${ }^{10}$.

Le montant des sommes dues varie fortement : il va de $1 / 2$ dinar $\left(n^{0} \mathbf{1 5}\right)$, pour la plus faible, à 110 dinars, voire plus si cette dernière somme ne correspond qu'à une partie de la dette $\left(\mathrm{n}^{\mathrm{o}} \mathbf{1 0}\right)$. Sur les 14 créances dont le montant est au moins en partie préservé, la moitié porte sur des sommes inférieures ou égales à 2 dinars. Elles sont la plupart du temps formulées en numéraire - en dinars avec ses subdivisions en qirāt -s et, dans un cas, en dirhams $\left(\mathrm{n}^{\mathrm{0}} \mathbf{8}\right)$-, mais un débiteur avait également contracté un prêt pour des semences de radis $\left(\mathrm{n}^{\circ} \mathbf{6}\right)$. Dans certains cas, la raison de l'emprisonnement n'apparaît pas ou a disparu. Les paragraphes 5, 16 et $\mathbf{1 7}$ correspondent probablement à des affaires d'argent; en revanche rien n'est précisé à propos de la femme Malak, dont le cas est laissé à la discrétion du juge $\left(\mathrm{n}^{\mathrm{0}} \mathbf{7}\right)$.

Tab. 1 : Montant des créances

\begin{tabular}{lc}
\hline Montant de la dette & Nombre de créances \\
\hline$<1$ dinar ${ }^{11}$ & 3 \\
$1-2$ dinars & 4 \\
$3-9$ dinars ${ }^{12}$ & 2 \\
$\geq 10$ dinars & 5
\end{tabular}

Cet extrait de registre témoigne ainsi de l'importance de la détention administrative pour dette, surtout connue jusqu'ici par le biais de la théorie juridique et des sources narratives ${ }^{13}$.

\footnotetext{
${ }^{9}$ Dans une pétition du $\mathrm{III}^{\mathrm{e}} / \mathrm{IX}^{\mathrm{e}}$ siècle, P.KhanPetitions 2 (provenant également de la collection Michaelidès), l'auteur se plaint au gouverneur d'un locataire qui ne paie pas son loyer. La somme due n'est pas appelée dayn dans la partie préservée du document, mais ḥaqq kirā («le montant du loyer »).

${ }^{10}$ Le terme qirād, généralement utilisé par les juristes mālikites et šăfi īites, est synonyme de mudāaraba, plutôt employé par les ḥanafites. Voir A. L. Udovitch, « Kirāḍ », EI², V, p. 132.

${ }^{11}$ Nous incluons le paragraphe $\mathrm{n}^{\circ} \mathbf{8}$, dans lequel la somme est exprimée en dirhams. Selon les équivalences mentionnées par E. Ashtor (A Social and Economic History of the Near East in the Middle Ages, Collins, Londres, 1976, p. 84), 4 dirhams $=1 / 3$ dinar.

${ }^{12}$ Nous incluons le paragraphe $\mathrm{n}^{\mathrm{O}} \mathbf{6}$, où la dette est de 2 dinars et deux mesures de graines de radis, en formulant l'hypothèse que ces deux mesures reviennent à un dinar au moins. Selon Ibn Mammātī (m. 606/1209), les radis ( fuğl) se cultivent toute l'année. Un à deux qadaḥ-s de semences sont nécessaires pour une récolte dont le prix est estimé de 4 à 6 dinars. Le ḩarāğ qui est perçu sur cette production est d'un dinar par faddān. Ibn Mammātī, Kitāa Qawānīn al-dawāwīn, éd. 'Azīz Sūryāl 'Ațiyya, Maktabat Madbūlī, Le Caire, 1991, p. 269. Cf. al-Maqrīzī, alMawā 'iz wa-l-i 'tibār fì dikr al-hnițaṭ wa-l-ātāâr, éd. Ayman Fu'ād Sayyid, Mu'assasat al-furqān li-l-turāt al-islāmī, Londres, 2002, I, p. 277.

${ }^{13}$ Voir H. 'A.-Ġ. Abū Ġudda, Ahkāam al-siğn wa-mu 'āmalat al-suğanā' fì l-islām, thèse de doctorat, Université de la Zītūna, Tunis, 1986 ; I. Schneider, «Imprisonment in Pre-classical and Classical Islamic Law », Islamic Law and Society, 2 (1995), p. 157-173 ; N. Hentati, « La prison en Occident musulman médiéval », Arabica, 54 (2007), p. 149-188 ; M. Tillier, «Prisons et autorités urbaines sous les Abbassides », Arabica, 55 (2008), p. 387-408 ; id., «Vivre en prison à l'époque abbasside », Journal of the Economic and Social History of the Orient, 52 (2009), p.
} 
Selon la première, l'endettement constituait le principal motif d'emprisonnement ${ }^{14}$. Certains juristes, comme le Médinois al-Zuhrī (m. 124/742) et l'Égyptien al-Layt b. Sa'd (m. 175/791) préféraient, semble-t-il, voir un débiteur insolvable travailler pour le créancier plutôt que le mettre aux fers ; le mālikite égyptien 'Abd Allāh b. 'Abd al-Ḥakam (m. 214/829) considérait encore qu'un débiteur insolvable, s'il était «homme de métier» (min ahl al-șinā 'āt), devait être remis à son créancier pour travailler chez lui et ainsi rembourser sa dette ${ }^{15}$. Cette opinion demeura cependant minoritaire ${ }^{16}$. Aux yeux de la majorité des mālikites, un débiteur qui se prétendait incapable de rembourser sa dette pouvait être emprisonné sans limitation de durée, jusqu'à ce qu'il se décide à rendre l'argent ou que le cadi acquière la certitude de son insolvabilité ${ }^{17}$. Les ḥanafites limitaient l'incarcération pour dette à une période de quatre à six mois ${ }^{18}$. Pour les šăfi ītes, la détention devait être très courte, le temps de vendre les biens du débiteur pour couvrir ses dettes ou de découvrir, par le biais d'enquêtes auprès de ses voisins ou de preuves légales, s'il était ou non en mesure de rembourser ; si on ne lui connaissait aucune possession, il devait prêter serment de son insolvabilité et être élargi ${ }^{19}$. Dans tous les cas, la prison était moins destinée à punir le débiteur qu'à faire pression sur lui pour qu'il rembourse son créancier ${ }^{20}$. Les sources distinguent la « prison du cadi », où étaient enfermés les débiteurs récalcitrants, de celle des voleurs et des criminels ${ }^{21}$. Si cette dichotomie s'appliquait à Fusțāt, notre registre concerne donc la première catégorie. Il montre que l'emprisonnement pouvait être décidé y compris pour des sommes relativement faibles, parfois bien inférieures à un dinar, comme dans le cas $n^{0} \mathbf{8}$.

\section{DES CRÉANCIERS DE FUSṬ̂̄Ṭ}

635-659; id., «Les prisonniers dans la société musulmane (II $/ \mathrm{VIII}^{\mathrm{e}}-\mathrm{IV}^{\mathrm{e}} / \mathrm{X}^{\mathrm{e}}$ siècle) », dans E. Malamut (éd.), Dynamiques sociales au Moyen Âge en Occident et en Orient, Publications de l'Université de Provence, Aix-enProvence, 2010, p. 191-212.

${ }^{14}$ E. Tyan, «Iflās et procédure d'exécution sur les biens en droit musulman (madhab hanafite) », Studia Islamica, 21 (1964), p. 145 sq. ; I. Schneider, «Imprisonment in Pre-classical and Classical Islamic Law », p. 158 sq. ; M. Tillier, «Les prisonniers dans la société », p. 193.

${ }^{15}$ Ibn 'Abd al-Hakam, al-Muhtașar al-șaḡìr, éd. 'Umar 'Alī Abū Bakr Zāriyā, Dār Ibn al-Qayyim-Dār Ibn 'Affān, Riad-Le Caire, 2012, p. 487. Voir également Ibn 'Abd al-Hakam, al-Muhtaṣar al-kabīr, éd. Ahmmad b. 'Abd alKarīm Nağīib, Markaz Nağībawayh, Dublin, 2011, p. 331.

${ }^{16}$ Al-Ṭahāwī et al-Ğașșāṣ, Muhtaṣar ihntilāf al- 'ulamā', éd. 'Abd Allāh Nad̄īr Aḥmad, Dār al-bašā'ir al-islāmiyya, Beyrouth, 1995, III, p. 395. On remarquera que Mālik comme al-Šāfi '̄ refusent que le débiteur insolvable soit mis au service de son créancier. Saḥnūn, al-Mudawwana l-kubrā, Maṭba'at al-sa'āda, Le Caire, 1323 H. (rep. Dār Ṣādir), V, p. 205 ; al-Šāfi ' ī, Kitāb al-umm, éd. Rif' at Fawzī 'Abd al-Muțalib, Dār al-wafā', al-Manșūra, 2001, IV, p. 442 Voir également I. Schneider, «Imprisonment in Pre-classical and Classical Islamic Law », p. 159-60.

${ }^{17}$ Saḥnūn, al-Mudawwana l-kubrā, V, p. 204. Cf. M. Tillier, «Les prisonniers dans la société », p. 193. Notons que selon le hanafite égyptien al-Ṭahāwī, Mālik semble avoir été moins favorable à l'emprisonnement pour dette que les fondateurs éponymes des autres écoles juridiques. Al-Ṭahāwī et al-Ğaṣṣāṣ, Muhntaṣar ihtilāf al- 'ulamā', III, p. 394.

${ }^{18}$ Voir al-Hașșāf, Kitāb Adab al-qāḍ̄ , éd. Farhāā Ziyāda, The American University in Cairo Press, Le Caire, 1978 , p. 254-263; M. Tillier, « Les prisonniers dans la société », p. 193.

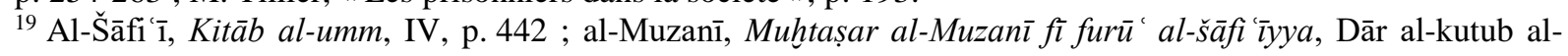
'ilmiyya, Beyrouth, 1998, p. 144.

${ }^{20}$ M. Tillier, «Les prisonniers dans la société », p. 193-194 ; N. Hentati, «La prison en Occident musulman médiéval », p. 153.

${ }^{21}$ I. Schneider, « Imprisonment in Pre-classical and Classical Islamic Law », p. 169. 
Sur les 18 affaires évoquées dans les pages conservées du registre, les noms de 25 parties (créanciers et débiteurs) sont préservés en partie ou en totalité. La majorité des personnages sont identifiés par leur ism suivi du nom de leur père, éventuellement suivi d'une nisba indiquant sa religion $\left(n^{\circ} \mathbf{1}\right)$, une qualité physique $\left(n^{\circ} 12\right)$ ou sa profession $\left(n^{o s} \mathbf{3}, 4,13\right)$. Dans quelques cas où le nom du père n'est pas mentionné, l'identité est précisée par le recours à un surnom ( «le Noir », $\left.\mathrm{n}^{\mathrm{o}} \mathbf{2}\right)$, à une nisba religieuse $\left(\mathrm{n}^{\text {os }} \mathbf{6}, \mathbf{8}\right)$ ou professionnelle $\left(\mathrm{n}^{\mathrm{os}} \mathbf{8}, \mathbf{1 4}\right)$, ou encore, pour une femme, par sa qualité d'épouse d'un individu $\left(\mathrm{n}^{\mathrm{0}} 7\right)$. Aucun de ces personnages ne porte de nisba tribale ou géographique. La plupart sont inconnus des sources littéraires. Notons cependant que Mubārak le Noir (al-Aswad) $\left(n^{\circ} 2\right)$ est le nom de l'homme qui tua le gouverneur égyptien 'Umayr b. al-Walīd (r. 214/829) lorsque ce dernier partit réprimer une révolte fiscale dans le Ḥawf (Delta). Selon al-Kindī, ce Mubārak al-Aswad était un client (mawlā) de Humayd b. Kawtar al-Ḥarašī (dont seul le nom est connu par les sources littéraires) ${ }^{22}$. La chronologie autorise à penser qu'il pourrait s'agir du même homme, qui aurait donc fait un séjour en prison pour cause d'endettement quelques années avant de s'illustrer dans l'embuscade au cours de laquelle le gouverneur fut tué. Le nom et le surnom sont cependant trop courants, en particulier dans le milieu servile, pour l'affirmer.

L'appartenance confessionnelle ou au moins communautaire de nombreux acteurs de ce registre peut être reconstituée. Deux individus sont explicitement qualifiés de «juifs $»\left(n^{\circ} \mathbf{1}\right)$, deux autres de «chrétiens » $\left(\mathrm{n}^{\text {os }} \mathbf{6}\right.$ et $\left.\mathbf{8}\right)$, tandis que l'onomastique à consonance copte de leurs adversaires respectifs laisse supposer qu'ils étaient, sinon de la même obédience, en tous cas de la même communauté. Les noms arabes des 19 personnages restants laissent présumer qu'il s'agit de musulmans ${ }^{23}$.

Tab. 2 : Religion des parties

\begin{tabular}{lc}
\hline $\begin{array}{l}\text { Religion présumée des } \\
\text { plaideurs }\end{array}$ & $\begin{array}{l}\text { Nombre } \\
\text { d'individus }\end{array}$ \\
\hline islam & 19 \\
christianisme & 4 \\
judaïsme & 2
\end{tabular}

Il convient de constater que, dans ces quelques pages, les relations de créance paraissent nettement confessionnalisées : un juif prête à un juif, deux chrétiens à deux autres chrétiens, et les musulmans font de même entre eux. Ces extraits ne préjugent pas de la possibilité de créances intercommunautaires, qui sont d'ailleurs attestées dans des documents contemporains

\footnotetext{
${ }^{22} \mathrm{Al}-\mathrm{Kind} \overline{1}$, Wulāt, p. 186. Sur cette révolte, voir G. Wiet, L'Égypte arabe de la conquête arabe à la conquête ottomane, 642-1517 de l'ère chrétienne (Histoire de la nation égyptienne, tome IV), Plon, Paris, 1937, p. 73-75 ; H. Kennedy, «Egypt as a Province of the Islamic Caliphate », dans C.F. Petry (éd.), The Cambridge History of Egypt, Cambridge University Press, Cambridge, 1998, p. 83.

${ }^{23}$ Marie Legendre a bien montré la difficulté d'interpréter l'appartenance religieuse d'un individu à partir de son nom (M. Legendre, « Perméabilité linguistique et anthroponymique entre copte et arabe : l'exemple de comptes en caractères coptes du Fayoum fatimide », dans A. Boud'hors, A. Delattre, C. Louis et T. S. Richter, Coptica Argentoratensia, de Boccard, Paris, 2014, p. 348-350). C'est pourquoi les développements qui suivent restent en partie hypothétiques.
} 
et plus tardifs ${ }^{24}$. Néanmoins, la série de cas mentionnés dans notre registre suggère que dans la Fusțât de la fin du VIII ${ }^{\mathrm{e}}$ ou du début du $\mathrm{IX}^{\mathrm{e}}$ siècle, les emprunts étaient souscrits de manière privilégiée au sein d'une même communauté religieuse.

Il ne faudrait pas pour autant conclure trop vite à la ségrégation spatiale des communautés. Le registre préserve en effet les adresses de deux créanciers non musulmans qui résidaient dans d'anciens quartiers tribaux, encore sans doute peuplés en grande partie de musulmans. Un chrétien habitait dans le quartier de Tuğîb, à l'est de Qaṣr al-Šam', l'ancienne Babylone demeurée le principal quartier non musulman de Fustạạt $\left(n^{0} \mathbf{8}\right)$ : ce muletier dont le nom n'est qu'en partie restituable résidait dans la maison dite de 'Abd Allāh b. Sahl, sans doute le propriétaire, dont le nom laisse supposer qu'il était musulman. Le juif 'Abd al-Malik b. Isḥāq demeurait quant à lui à al-Rāya, c'est-à-dire l'ancienne hitṭa des ahl al-Rāya (les «Gens de l'Étendard »), en plein cœur de Fusțāt $\left(n^{\circ} \mathbf{1}\right)$. Le quartier était prévu à l'origine pour réunir les divers groupements tribaux qui constituaient le cœur de l'armée conquérante autour de 'Amr b. al- 'Ạṣ ${ }^{25}$. Au début du IX ${ }^{\mathrm{e}}$ siècle, il constituait encore un quartier aristocratique, dont W. Kubiak souligne le caractère de plus en plus cosmopolite ${ }^{26}$. Le créancier y habitait une «maison des juifs » qui, d'après son nom, devait être célèbre pour abriter plusieurs membres de cette communauté. Ces deux adresses témoignent d'une mixité confessionnelle au sein des quartiers centraux de Fustạt ${ }^{27}$.

Les parties dont il est question dans nos papyrus appartiennent, autant qu'on puisse en juger par les professions ou les relations de clientélisme mentionnées, aux catégories sociales modestes de la population de la capitale égyptienne. On relève la présence parmi les emprunteurs d'un teinturier $\left(n^{\circ} 3\right)$, d'un presseur $\left(n^{\circ} 13\right)$ et d'un fossoyeur $\left(n^{\circ} 14\right)$, ce dernier appartenant sans doute aux catégories sociales les plus basses. Parmi les créanciers figurent un boucher $\left(n^{\circ} \mathbf{4}\right)$, un muletier $\left(n^{\circ} \mathbf{8}\right)$ et un presseur $\left(n^{\circ} \mathbf{1 3}\right)$. Dans la vignette $n^{0} 3$, le créancier, Nāfi', n'est pas identifié par le nom de son père mais par celui de son patron : ce mawlā était selon toute vraisemblance un esclave affranchi, et non un simple converti rattaché à une tribu, et le nom de son patron constituait son nouveau nasab. Le cas $\mathrm{n}^{\mathrm{o}} \mathbf{1 0}$ constitue peut-être une exception : le qirāọ contracté par Muḥammad b. Muhrim, qui s'élevait vraisemblablement à 110 dinars, suggère qu'il s'agissait d'un commerçant assez ambitieux pour envisager un investissement important, et que son créancier Ismā' îl b. Mūsā était un homme aisé, peut-être un riche marchand. Le neveu de Muḥammad b. Muhrim $\left(\mathrm{n}^{\circ} \mathbf{1 0}\right)$ était assez fortuné pour se porter garant et rembourser tout ou partie de sa dette. Ces quelques exemples laissent enfin penser que les emprunts étaient souscrits de manière privilégiée au sein d'un même milieu

\footnotetext{
${ }^{24}$ Voir par exemple N. Vanthieghem, « Contribution à l'histoire de la transition du papyrus au papier. À propos de la date de P. Ryl. Arab. I X, $10 »$, Chronique d'Égypte, 90 (2015), p. 423-430, ainsi que M. Tillier et $\mathrm{N}$. Vanthieghem, «La rançon du serment. Un accord à l'amiable au tribunal fatimide de Țalìt », Revue des mondes musulmans et de la Méditerranée, 140 (2016), p. 63.

${ }^{25}$ Voir W. Kubiak, Al-Fustat, p. 62, 68.

${ }^{26}$ W. Kubiak, Al-Fustat, p. 95.

${ }^{27}$ Une communauté juive demeurait à Babylone avant la conquête. Sur la base de sources littéraires, W. Kubiak conclut que des juifs s'installèrent ensuite à Fusțâț (W. Kubiak, Al-Fustat, p. 84). Notre registre semble constituer la première attestation documentaire du bien-fondé de cette conclusion.
} 
social, voire d'une même profession comme en témoigne le cas $\mathrm{n}^{\mathrm{o}} \mathbf{1 3}$, où le débiteur comme le créancier exercent le métier de presseur.

Tab. 3 : Profession des parties

\begin{tabular}{cc}
\hline Débiteur & Créancier \\
\hline teinturier & $?$ \\
$?$ & boucher \\
$?$ & muletier \\
presseur & presseur \\
fossoyeur & $?$
\end{tabular}

À une exception près, les adresses des débiteurs ne sont pas signalées, sans doute parce que ceux-ci étaient en prison au moment de la consignation de leurs noms dans le registre. En revanche, celles des créanciers sont enregistrées de manière quasi systématique : non seulement elles participaient à l'identification de ces personnages - que les caractéristiques mentionnées ne suffisaient certainement pas à distinguer d'éventuels homonymes dans le dense tissu urbain de Fuștāṭt ${ }^{28}$-, mais elles permettaient en outre de les retrouver pour leur verser l'argent de la créance ou encore pour les convoquer au tribunal. Le fiqh préconise en effet qu'un cadi enquête régulièrement sur les débiteurs détenus et convoque leurs créanciers afin de vérifier la nécessité de les maintenir en prison ${ }^{29}$.

Les adresses des créanciers sont en général présentées sous forme tripartite, en commençant

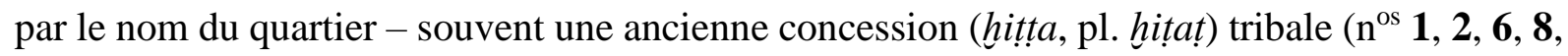
$10,11 ?, 12,16)$. On mentionne ensuite un point de repère connu, comme un hammam ( $\mathrm{n}^{\text {os }} \mathbf{1}$ et 13), une caserne $\left(\mathrm{n}^{\mathrm{os}} \mathbf{6}\right.$ et $\left.\mathbf{8}\right)$, une demeure ou un palais célèbre $\left(\mathrm{n}^{\mathrm{o}} \mathbf{1 0}\right)$. Enfin, la maison où réside le créancier est indiquée, désignée soit par le nom de son propriétaire présent ou passé $\left(n^{\text {os }} \mathbf{2}, \mathbf{6}, 8\right.$ et 12), soit par une appellation notoire $\left(n^{\circ} \mathbf{1}\right)^{30}$. Cette structure d'adresse semble avoir été habituelle à l'époque : dans un reçu de loyer pour une maison qui appartenait très certainement aux fameux marchands d'étoffes du Fayoum étudiés par Y. Rāgigib ${ }^{31}$, la localisation de la maison louée est indiquée en précisant le quartier ainsi que le bâtiment connu le plus proche ${ }^{32}$.

\footnotetext{
${ }^{28}$ Voir M. Tillier, «L'identification en justice à l'époque abbasside », Revue des mondes musulmans et de la Méditerranée, 127 (2010), p. 106.

${ }^{29}$ Voir M. Tillier, Les cadis d'Iraq et l'État abbasside (132/750-334/945), Presses de l'Ifpo, Damas, 2009, p. 408410 ; id., «Les prisonniers dans la société », p. 194 ; id. «L'identification en justice », p. 101.

${ }^{30} \mathrm{Cf}$. la manière dont le figh recommande de mentionner les adresses des témoins dans un procès dans M. Tillier, «L'identification en justice », p. 101.

${ }^{31}$ Voir en dernier lieu les corrections de N. Vanthieghem, « Papyrologica IV », Chronique d'Égypte, 91 (2016), p. 444-445.

${ }^{32}$ P.David-WeillLouvre 20a.5. L'éditeur avait lu allatī fì ru' '... fì mah ... fadī'a. Il convient de lire allatī fì Ru' ayn fi mahras Fahd. La structure des adresses semble avoir été plus élémentaire au $\mathrm{II}^{\mathrm{e}} / \mathrm{VIII}{ }^{\mathrm{e}}$ siècle, comme le suggère P.Worp 65, une liste de « compagnons » éditée par P. Sijpesteijn. Le scribe y mentionne au choix un quartier tribal, un marché ou un bâtiment connu où se trouve la résidence (manzil) de la personne. P.M. Sijpesteijn, «A Seventh/Eighth-century List of Companions from Fusțāt », dans F. Hoogendijk (éd.), Sixty-Five Papyrological Texts presented to Klaas A. Worp on the Occasion of his 65th Birthday, Brill, Leyde, 2008, p. 370-372.
} 
Quand l'enregistrement ne comporte pas d'adresse, c'est que le créancier peut être aisément localisé sans qu'il y ait besoin de préciser son domicile. Dans la vignette $n^{\circ} \mathbf{4}$, le créancier est un boucher du souk Barbar, lieu bien connu qui constituait un quartier à part entière où il devait être facile de retrouver un boucher identifié nominalement. Un autre cas intéressant se lit dans la vignette $n^{0} \mathbf{3}$ où l'adresse de Nāfi' est omise sans doute parce que son patron jouissait d'une notoriété suffisante pour que l'on puisse se dispenser de signaler son quartier de résidence. Quant au fossoyeur Sālim ( $\left.{ }^{0} \mathbf{1 4}\right)$, son débiteur devait être un de ses collègues vivant dans un simple «gourbi » près du cimetière, sans plus d'identification.

Carte 1 : Les quartiers centraux de Fusțāt au début du IX siècle

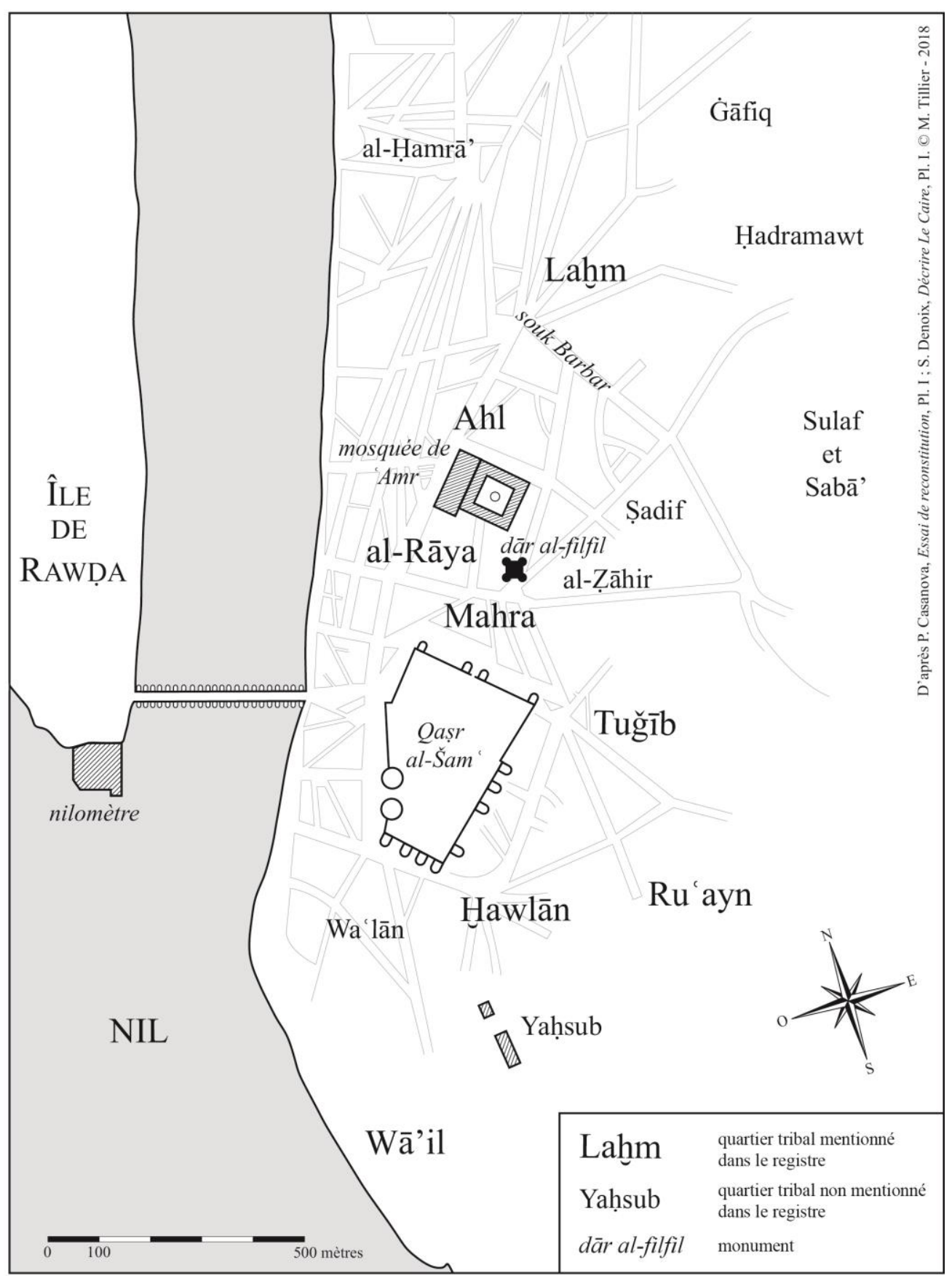


Les adresses préservées et identifiables permettent de cartographier de manière approximative les lieux de résidence des créanciers. Elles appartiennent toutes à des quartiers centraux de Fusțât, échelonnés entre le nord de la mosquée de 'Amr (Laḩm, souk Barbar) et le sud de Qașr al-Šam ' (Wā'il), le plus «excentré » étant Ru'ayn, qui se trouvait sur les hauteurs à l'est de Qaṣr al-Šam'. Ces quartiers constituaient le 'amal fawq, à cette époque le centre populaire historique de Fusțât, alors que le pouvoir, depuis l'arrivée des Abbassides, s'était établi dans la frange septentrionale de la ville, à al- 'Askar ${ }^{33}$. Il est probable que les débiteurs emprisonnés, dont les adresses ne sont pas consignées, résidaient dans la même aire géographique. Toutes les parties mentionnées, quelle que fût leur confession, se retrouvèrent devant les mêmes institutions musulmanes à l'occasion de leurs procès.

\section{INSTITUTIONS JUDICIAIRES ET CARCÉRALES}

\subsection{Gouverneur et cadi}

L'institution à l'origine de l'incarcération n'est mentionnée qu'une fois, au paragraphe $\mathrm{n}^{\mathrm{o}} \mathbf{7}$ : un cadi, non nommé, a écrit à Faḍāla b. al-Mufaḍḍal, lui-même «vicaire » de 'Abd Allāh b. Muhammad, pour lui ordonner d'emprisonner une femme, Malak. Le titre de 'Abd Allāh b. Muhammad n'est pas précisé, mais l'eulogie $a b q \bar{a}-h u$ Allāh («que Dieu prolonge son existence ! ») qui l'accompagne témoigne de son haut rang; dans les documents administratifs, elle suit en général le nom des califes ${ }^{34}$, des gouverneurs ${ }^{35}$ ou des surintendants des finances ${ }^{36}$. Il s'agit selon toute vraisemblance du gouverneur d'Égypte 'Abd Allāh b. Muhammad al'Abbāsī (r. 189-190/805-806), dit Ibn Zaynab ${ }^{37}$. Si cette identification est correcte, le contexte fusțātien de nos affaires implique que le cadi anonyme dont il est question est 'Abd al-Raḥmān b. 'Abd Allāh al- 'Umarī, un juriste mālikite d'origine médinoise qui fut en poste à la judicature de Fustật de 185 à 194/801 à $810^{38}$.

Selon la littérature juridique, le cadi pouvait emprisonner un débiteur sur demande de son adversaire, à condition que l'existence de la dette soit prouvée par l'aveu (iqrār) du défendeur ou le double témoignage honorable (bayyina) produit par le demandeur ${ }^{39}$. Dans notre registre,

\footnotetext{
${ }^{33}$ Voir J. Jomier, « al-Fusțāṭ », EI ${ }^{2}$, II, p. 980 ; W. Kubiak, Al-Fustat, p. 11, 129.

${ }^{34} \mathrm{Cf}$. par exemple $C P R$ XXI $44,5$.

${ }^{35}$ Cf. CPR XXI 5, 4 et 56, 5 ainsi que P. Grohmann Probleme 17, 3-4 et 18, 2.

${ }^{36}$ Cf. P. Grohmann Urkunden 13, 6-7 et P. Ryl. Arab. I, III 11, 8-9 (où il faut lire le nom Abū 1-Hasan Mūsā b. Ğa 'far et non Abū l-Ḥasan Mūsā b. Șaqar). L'utilisation des eulogies dans les documents privés obéit à des règles différentes. Voir E.M. Grob, Documentary Arabic Private and Business Letters on Papyrus. Form and Function, Content and Context, De Gruyter, Berlin-New York, 2010, p. 33-38.

${ }^{37}$ Al-Kindī, Wulāt, p. 141-142. Le nom de ce gouverneur a parfois été lu 'Ubayd Allāh b. Muhammad (voir E. de Zambaur, Manuel de généalogie et de chronologie pour l'histoire de l'Islam, Heinz Lafaire, Hanovre, 1927, p. 27). De fait, des poids de verre produits sous le même gouverneur portent alternativement les noms de 'Abd Allāh et de 'Ubayd Allāh b. Muhammad. Voir P. Balog, Umayyad, 'Ābbasid (sic) and Țūlūnid Glass Weights and Vessel Stamps, The American Numismatic Society, New York, 1976, p. 222-223 (n ${ }^{\text {os }} 630,631$ ).

${ }^{38}$ Al-Kindī, Ahbār quḍāt Miṣr, dans The Governors and Judges of Egypt, éd. R. Guest, Brill, Leyde, 1912 p. $394-$ 411 ; trad. dans al-Kindī, Histoire des cadis égyptiens, trad. M. Tillier, Ifao, Le Caire, 2012, p. 160-178. L'Égypte disposait à cette époque d'autres cadis dans ses grandes villes à forte proportion musulmane, comme Alexandrie (voir M. Tillier, « Introduction », dans al-Kindī, Histoire des cadis égyptiens, p. 23). Fusțât ne disposait cependant que d'un seul cadi.

${ }^{39}$ Al-Hुașșāf, Adab al-qāọ̄i, p. 254.
} 
les débiteurs ont tous été emprisonnés sur la base de leur aveu. Il n'est que dans le cas de la femme Malak $\left(n^{\circ} 7\right)$ qu'aucune forme de preuve n'est mentionnée - mais encore une fois son affaire semble particulière. Les vignettes $n^{\text {os }} 14,15,16$ et 17 ne contiennent pas de preuve, mais sans doute est-ce dû à des lacunes dans le texte. L'absence de toute preuve testimoniale - la reine des preuves dans le fiqh classique - pourrait surprendre. Il semble que les débiteurs n'aient pas cherché à nier l'accusation de leurs adversaires, qui n'eurent donc pas besoin de produire des témoins.

Le cas de Muhammad b. Muhrim ( $\left.\mathrm{n}^{\mathrm{o}} \mathbf{1 0}\right)$ est particulier : comme les autres défendeurs, celuici a commencé par avouer l'existence d'une dette. Il a néanmoins prétendu l'avoir déjà remboursée et pouvoir en apporter la preuve, en présentant les quittances (barā'āt) que son adversaire, Ismā' $\overline{1} l$ b. Mūsā, avait rédigées lors du remboursement ${ }^{40}$. Il se voit donc incarcéré en attendant qu'il produise ces documents ou, à défaut, se décide à rembourser la créance. Il aurait cependant pu échapper à la prison en instituant un garant. Le fiqh stipule en effet qu'en attendant la production de preuves par le demandeur, le débiteur peut fournir un kafil (garant), à condition toutefois que le créancier le considère comme digne de confiance (tiqa $)^{41}$. Pour les hanafites, le garant est nommé pour trois jours, au terme desquels il doit faire comparaître le débiteur (kafāla bi-l-nafs) ou est tenu de payer la dette à sa place si le défendeur profite de sa liberté pour disparaître (kafāla bi-l-māl) ${ }^{42}$. Dans le cas qui nous occupe, le garant réclamé est appelé hamīl, terme qui désigne un type de garant spécifique qui se substitue au débiteur lorsque la dette arrive à échéance et que celui-ci ne parvient pas à la rembourser. La hamāla produit un effet libératoire sur le débiteur: le créancier ne peut plus se retourner contre lui, mais uniquement contre le garant. Ce dernier ne peut pas non plus attaquer le débiteur, auquel il a offert de régler sa dette ${ }^{43}$. Dans notre cas, un garant semble réclamé au débiteur Muhammad b. Muhrim car celui-ci prétend avoir déjà remboursé sa dette mais n'en a pas de preuve immédiatement disponible : fournir un garant doit lui permettre d'aller chercher les quittances qui pourront appuyer ses dires ; s'il a menti et échappe à la justice, le garant paiera l'ensemble de sa dette à sa place. Dans un premier temps, Muḥammad b. Muhrim déclare n'avoir aucun hamīl à proposer et se voit de ce fait incarcéré. Son cas est consigné dans le registre alors que l'affaire en est à ce stade. Un ajout postérieur vient cependant préciser qu'une solution a été trouvée: Muḥammad b. Nașr b. Muḥrim, sans doute un neveu paternel du prévenu, s'est porté garant (le verbe employé semble ḍamina) et a, peut-être, déjà versé au

\footnotetext{
${ }^{40}$ Sur la forme des quittances, voir al-Ṭaḥāwī, al-Šurūt al-șagì̃r, mudaylan bi-mā 'utira 'alay-hi min al-Šurūt alkabìr, éd. Rawhị Ūzğān, Bagdad, Maṭba at al- 'Ānī, 1974, p. 533 sq., ainsi que L. Daaïf, « Barā'a : réflexion sur la fonction et l'évolution de la structure de la quittance », Annales islamologiques, 48 (2014), p. 3-60.

${ }^{41}$ Ainsi est-il question dans $P$. Ryl. Arab. I, I 15 de la libération d'un prisonnier pour dette après qu'une personne de confiance a garanti le remboursement de la somme.

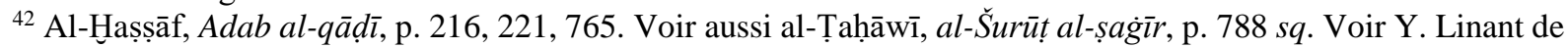
Bellefonds, « Kafāla », $E I^{2}$, IV, p. 422-423.

${ }^{43}$ Voir D. Santillana, Istituzioni di diritto musulmano malichita con riguardo anche al sistema sciafiita, Istituto per l'Oriente, Rome, 1938, II, p. 492-493. Sur la théorie de la hamāla dans l'Égypte du III//IXe siècle, voir également Ibn 'Abd al-Ḥakam, al-Muhtașar al-șagì r , p. 485-487. Notons que le verbe hamala indique également la désignation d'un garant dans $P$. Muslim State 13, 10.
} 
créancier la somme de 110 dinars - dont on ne sait s'ils correspondent à tout ou partie de la dette -, à la suite de quoi le détenu a été libéré.

Selon les ouvrages de fiqh, le cadi devait tenir un registre dans lequel il consignait les noms des débiteurs qu'il envoyait en prison ainsi que ceux de leurs adversaires, les sommes réclamées et les dates précises (jour, mois, année) des incarcérations ${ }^{44}$. La date, explique le hanafite alĞașsāạ (m. 370/980), était d'une grande importance, car elle permettait de calculer à quel moment le détenu qui ne s'était pas acquitté de sa dette devait être libéré : au bout de quatre mois environ, dit-il, le cadi devait élargir le débiteur et prononcer sa banqueroute (iflās ${ }^{45}$. En attendant, le juge était supposé diligenter une enquête auprès des voisins dignes de foi (iqqāt) du débiteur et de ses connaissances afin d'estimer sa solvabilité ${ }^{46}$. Le hanafite égyptien alṬạāwī (m. 321/933) consacre même un court chapitre - une page dans l'édition imprimée - à l'enregistrement d'un détenu pour dette par le cadi ${ }^{47}$. En dépit de certaines similitudes avec de tels registres de cadis, les extraits que nous publions ne ressortissent pas à la même catégorie. Nous y reviendrons.

Bien que le cadi ne soit mentionné qu'à propos de Malak - dont l'affaire, qui n'est pas exposée, semble différente de celle des autres détenus -, la théorie juridique suggère que les autres plaideurs du registre comparurent devant le même juge et que ce dernier fut à l'origine de leur incarcération. Néanmoins, l'affaire $n^{\circ} \mathbf{1 0}$ rend le tableau plus complexe. En effet, en toute logique, c'est le cadi qui aurait dû demander à Muḥammad b. Muhrim d'instituer un garant en attendant que le prévenu produise la preuve de son innocence. Or il n'en est rien : c'est un certain Faḍāla b. al-Mufaḍḍal qui le lui a ordonné, comme s'il avait instruit l'affaire depuis le début. Il convient dès lors de s'interroger sur le rôle de ce personnage.

\subsection{Un préfet de police}

Faḍāla b. al-Mufaḍḍal est cité dans deux entrées. Présenté comme le «vicaire » (halīfa) de 'Abd Allāh b. Muhammad - dont nous avons vu qu'il s'agissait selon toute vraisemblance du gouverneur -, il est d'abord le destinataire d'une lettre du cadi dans laquelle ce dernier lui ordonne d'incarcérer une prévenue $\left(\mathrm{n}^{\circ} \mathbf{7}\right)$. Dans l'entrée $\mathrm{n}^{\circ} \mathbf{1 0}$, il somme le débiteur d'instituer un garant.

\footnotetext{
${ }^{44}$ Al-Hașsāâ, Adab al-qā d̦, p. 254.

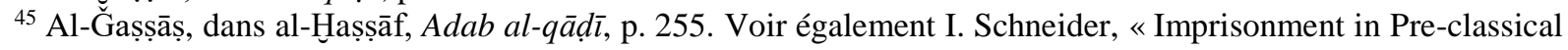
and Classical Islamic Law», p. 159. Sur l'iflās, voir E. Tyan, «Iflâs et procédure d'exécution sur les biens », p. 145-166 ; L. Milliot et F.-P. Blanc, Introduction à l'étude du droit musulman, Dalloz, Paris, 2001, p. 469-74. Lorsque la banqueroute était prononcée, le créancier devait attendre que la situation financière de son débiteur s'améliore pour à nouveau lui réclamer son argent en justice. Seuls les hanafites l'autorisaient à recourir à la mulāzama, une forme de harcèlement consistant à suivre continuellement son débiteur. Voir F.J. Ziadeh, «Mulāzama or Harassment of Recalcitrant Debtors in Islamic Law », Islamic Law and Society, 7 (2000), p. 289299. Pour un exemple plus tardif de pétition dans laquelle un prisonnier demande à comparaître devant un cadi šāfi îte, peut-être afin d'être déclaré en faillite et d'être ainsi libéré, voir P.M. Sijpesteijn, «Financial Troubles: a Mamluk Petition », dans A.E. Franklin, R.E. Margariti, M. Rustow et U. Simonsohn (éds.), Jews, Christians and Muslims in Medieval and Early Modern Times: a Festschrift in Honor of Mark R. Cohen, Brill, Leyde, 2014, p. 364.

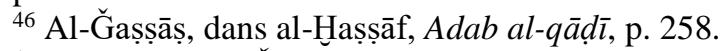

${ }^{47} \mathrm{Al}-$ Ṭaḥāwī, al-Š́rūut al-șag̀ìr $r$ p. 1146.
} 
Faḍāla b. al-Mufaḍḍal est connu des sources biographiques égyptiennes. Abū Tawāba Faḍāla b. al-Mufaḍḍal b. Faḍāla al-Ru'aynī al-Qitbānī al-Mișrī était le fils du cadi de Fusțāt alMufaḍ̣al b. Faḍāla qui fut en poste à trois reprises entre 168/784-785 et 177/793 ${ }^{48}$. Il apparaît chez al-Dahabī comme un traditionniste qui étudia le hadith auprès de son père et le transmit, notamment, à Yaḥyā b. 'Uțmān b. Șāliḥ al-Sahmī et à Abū l-Aḥwaṣ Muḥammad b. al-Haytam. Il serait mort en $226 / 841^{49}$. Sa réputation de traditionniste laisse à désirer aux yeux de certains : il se serait notamment adonné à la boisson et aurait joué aux échecs en pleine mosquée ${ }^{50}$. Cette image négative s'explique sans doute par les fonctions qu'il occupa à une époque de sa vie : selon Ibn Nāșir al-Dīn (m. 842/1438), il fut en effet « en charge de la police de Fustạaṭ » ('alā šurțat Mișr ${ }^{51}$.

La manière dont le registre présente Faḍāla $b$. al-Mufaḍḍal suggère qu'il exerçait de fait la fonction de préfet de police (șâhib al-šurța) à cette époque : en Égypte, ce personnage jouait en effet le rôle de «vicaire » du gouverneur qui l'avait nommé, le remplaçait lorsqu'il était en déplacement, ou assurait l'intérim entre deux gouverneurs ${ }^{52}$. Faḍāla n'apparaît pas dans la liste des șăhib-s al-šurța qu'al-Kindī propose pour chaque gouverneur, ni dans celle établie à l'époque contemporaine par Ḥusām 'Abd al-Zāhir ${ }^{53}$. Selon al-Kindī, le gouverneur 'Abd Allāh b. Muḥammad aurait eu successivement pour préfet de police Aḥmad b. Huwayy b. Huwayy al- 'Uḍrī et Muhammad b. 'Assāma b. 'Amr ${ }^{54}$. S'il ne s'agit pas d'une simple négligence, il est possible que Faḍāla ait été oublié par al-Kindī en raison de la brièveté de son mandat : comme le montre 'Abd al-Z̄āhir, les șạhib al-šurța de Fusțāt se succédaient à un rythme rapide, et ceux qui exerçaient un temps cette fonction y revenaient rarement par la suite ${ }^{55}$. Il se peut par ailleurs qu'al-Kindī se contente de mentionner le șâhhib al-šurța le plus proche du gouverneur.

Au II /VIII siècle, la šurța de Fusțāt était en effet bicéphale. Depuis la période omeyyade, elle se divisait en deux branches, l'une chargée de la sécurité du gouverneur et l'autre du

\footnotetext{
${ }^{48}$ Sur ce cadi, voir en dernier lieu M. Tillier, « Deux papyrus judiciaires de Fusțât (II /VIII ${ }^{e}$ siècle) », Chronique d'Égypte, 89 (2014), p. 412-445, en part. p. 426-428.

${ }^{49}$ Al-Dַhabī, Ta'rīhh al-islām, éd. 'Umar 'Abd al-Salām Tadmurī, Dār al-kitāb al- arabī, Beyrouth, 1987, XVI, p. 318 ; Ibn Zabr al-Raba '̄̄, Ta'rīh mawlid al- 'ulamā' wa-wafayāti-him, éd. 'Abd Allāh b. Ahmad b. Sulaymān alḤamad, Dār al-'āṣima, Riyad, 1410 H., p. 499. Le fils de Faḍāa, al-Mufaḍdal b. Faḍāla b. al-Mufaḍdal (m. 252/866) est également répertorié ; voir sa biographie dans Ibn Yūnus, Ta'rīh , I, p. 483. La famille de Faḍāla b. al-Mufaḍạal est connue par le matériel papyrologique : son père apparait dans un document judiciaire qui enregistre un mandataire pour le règlement d'une affaire de dette (M. Tillier, « Deux papyrus judiciaires », p. 423437) ; quant à son fils, il est mentionné dans deux lettres (P. Yale Inv. 2681 et P. Cambr. UL Inv. Michael. A 1368, cités par Kh. M. Younes, Joy and Sorrow, p. 19).

${ }^{50}$ Al-'Uqaylī, Kitāb al-ḍu 'afā' al-kabìr, éd. 'Abd al-Mu'ṭī Amīn Qal'ağīi, Dār al-kutub al- 'ilmiyya, Beyrouth, 1984, III, p. 456.

${ }^{51}$ Ibn Nāṣir al-Dīn, Tawdịh al-muštabih fì dabt asmā' al-ruwāt wa-ansābi-him wa-alqābi-him wa-kunā-hum, éd. Muḥammad Nu aym al- 'Araqsūsī, Mu'assasat al-risāla, Beyrouth, 1993, VII, p. 47. Sur l'image négative attachée aux policiers à l'époque abbasside, voir M. Tillier, Les cadis d'Iraq et l'État abbasside, p. 660.

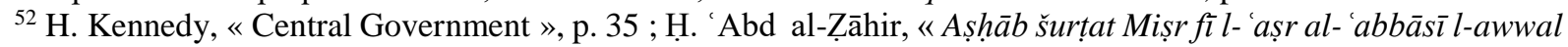
[132-232 H./749-847 M.] (ru'ya ğadīda fì daw' al-ihsāa' al-tārīhñ̄) », Annales islamologiques, 36 (2002), p. 1-22, p. 7.

${ }^{53}$ H. 'Abd al-Z̄āhir, «Așhāb šurțat Mișr », p. 14-22.

${ }^{54}$ Al-Kindī, Wulāt, p. 142.

${ }^{55}$ Ḥ. 'Abd al-Zāhir, "Așhāb šurțat Miṣr », p. 9-10. Al-Kindī oublie d'autres personnages dans son ouvrage, comme le gouverneur Huwway b. Huwway ; voir Kh. Younes, « New Governors identified in Arabic Papyri », dans A. Delattre, M. Legendre et P.M. Sijpesteijn (éd.), Authority and Control in the Countryside, Late Antiquity and Early Islam: Continuity and Change in the Mediterranean 6th-10th Century, Brill, Leyde, à paraitre.
} 
maintien de l'ordre urbain ${ }^{56}$. À la fin du siècle, sous les Abbassides, cette dichotomie se traduisait dans l'espace : la šurțat al- 'ulyā (aussi appelée šurțat al-fawq ou šurțt al- 'Askar) avait juridiction dans la partie nord de l'agglomération, c'est-à-dire en particulier la ville gouvernementale d'al-'Askar. La šurțtat al-asfal (ou šurțtal-madīna) étendait son autorité sur la partie sud, c'est-à-dire la Fusțât historique. Chacune des deux polices disposait de son préfet ${ }^{57}$. La distribution géographique des plaideurs mentionnés dans notre registre permet de supposer que Faḍāla b. al-Mufaḍḍal exerçait à l'époque la fonction de chef de la šurțat al-asfal, celle dont la juridiction s'étendait sur le centre-ville ancien. Le siège de cette police se trouvait alors au sud de la mosquée de 'Amr, dans la dār al-filfil (palais du Poivre) aussi qualifiée, dans les sources, de dār al-ma ‘ūna et de dār al-šurța (hôtel de police) ${ }^{58}$. Une vingtaine d'années après la rédaction de nos documents, en 213/828-829, un nouvel hôtel de police fut édifié suite à l'agrandissement de la mosquée de 'Amr ; il fut transformé en prison à la fin du $\mathrm{IV}^{\mathrm{e}} / \mathrm{X}^{\mathrm{e}}$ siècle, après l'arrivée des Fatimides ${ }^{59}$.

Selon les sources littéraires, le șạhib al-šurța disposait d'attributions variées. Il était non seulement en charge du maintien de l'ordre et de la répression du crime au sein de la ville, mais se voyait aussi conférer un pouvoir «exécutif, consistant dans l'application des peines et l'exercice de l'administration pénitentiaire »; il devait ainsi «prêter main-forte aux magistrats judiciaires pour l'accomplissement des actes de procédure et l'exécution des jugements » ${ }^{60}$. Émile Tyan souligne, en s'appuyant sur Ibn Qutayba, qu'à l'époque omeyyade les agents de la šurța semblent avoir joui de prérogatives élargies, leur permettant de statuer dans des litiges matrimoniaux ou des conflits de propriété, et d'emprisonner des débiteurs récalcitrants ${ }^{61}$. L'un de nous a par ailleurs souligné l'ambiguïté du rôle assigné à la šurța dans l'administration des prisons : alors qu'en théorie, le fiqh considère que la «prison du cadi », celle où étaient incarcérés les débiteurs, relève de l'autorité exclusive de celui-ci, dans la pratique il semble que le pouvoir politico-militaire incarné par le gouverneur et par le șâhib al-šurța contrôlait largement le système carcéral, y compris la «prison du cadi » ${ }^{62}$. Toutes les pétitions que nous conservons de l'époque abbasside et qui concernent des cas de dettes non recouvrées sont par ailleurs adressées au gouverneur d'Égypte, et non au cadi comme on l'attendrait ${ }^{63}$. Cela suggère que ce type d'affaire, en particulier lorsqu'une incarcération était en jeu, relevait en priorité de l'autorité politico-militaire.

Notre registre laisse transparaître une répartition des rôles entre le cadi et le șạhhib al-šurța. Dans l'entrée $\mathrm{n}^{\circ} \mathbf{7}$, l'incarcération est prononcée par le cadi, dans le cadre d'un procès, mais l'exécution est confiée par le cadi au șạhib al-šurța. Ce dernier, qui reçoit du cadi un «ordre » écrit, lui est subordonné en la matière. Le rôle assigné à Faḍāa b. al-Mufaḍ̣al semble

\footnotetext{
${ }^{56}$ S. Bouderbala, Ǧund Miṣr : étude de l'administration militaire d'Égypte des débuts de l'Islam, 21/642-218/833, Thèse de doctorat, Université Paris 1 Panthéon-Sorbonne, 2008, p. 252-255.

${ }^{57}$ E. Tyan, Histoire de l'organisation judiciaire en pays d'Islam, 2e édition, Brill, Leyde, 1960, p. 579-580.

${ }^{58}$ S. Denoix, Décrire Le Caire, p. 107 ; S. Bouderbala, Ğund Mișr, p. 112.

${ }^{59}$ Al-Maqrīzī, al-Mawā 'iz wa-l-i 'tibār, III, p. 597-598.

${ }^{60}$ E. Tyan, Histoire de l'organisation judiciaire, p. 589.

${ }^{61}$ E. Tyan, Histoire de l'organisation judiciaire, p. 608.

${ }^{62}$ M. Tillier, « Prisons et autorités urbaines », p. 393-395.

${ }^{63}$ Voir entre autres $P$. World, p. $186-187$ et P. Khan Petitions 1.
} 
néanmoins dépasser celui d'un simple administrateur. Dans l'entrée $\mathrm{n}^{\mathbf{0}} \mathbf{1 0}$, comme nous l'avons vu plus haut, le șâhib al-šurța prend l'initiative de demander un garant à Muhammad b. Muhrim, réclamation que l'on attendrait plutôt du cadi avant que ce dernier ne prononce l'incarcération. Deux hypothèses permettent d'expliquer ce cas : (1) Faḍāla b. al-Mufaḍdal réclame un garant au débiteur alors que celui-ci est déjà incarcéré, suite à la pétition que celuici lui a fait parvenir. Peut-être le cadi lui avait-il auparavant demandé un tel garant, et le prévenu avait-il déjà refusé d'en fournir un. Nous allons revenir sur cette hypothèse en étudiant le processus de pétition. (2) L'ensemble de la procédure s'est déroulé devant Faḍāa b. alMufaụḍal, ce qui signifierait que le șăḥib al-šurța jouissait, en ce début de $\mathrm{IX}^{\mathrm{e}}$ siècle, de prérogatives judiciaires étendues, et que certains plaideurs s'adressaient directement à lui pour des affaires de dette.

\section{INCARCÉRATION ET PROCESSUS DE PÉTITION}

L'administration des prisons par la šurța, souligne E. Tyan, impliquait la tenue de registres des détenus ${ }^{64}$. Il fallait enregistrer les entrées et les sorties, ainsi que les affaires ayant conduit à l'incarcération. De même, à peine investi, le cadi devait enquêter sur les débiteurs enfermés dans sa prison et en vérifier les registres ${ }^{65}$. Nos fragments correspondent pourtant à un type particulier de registre, non point destiné en priorité à consigner les entrées et les sorties, mais à enregistrer les pétitions des prisonniers. Le terme polysémique qișsa (pl. qiṣaș), qui introduit chaque paragraphe, peut prendre le sens général d' «affaire »; dans un contexte judiciaire, cependant, le mot est employé dès l'époque abbasside pour désigner la "pétition » qu'un plaideur peut produire devant un juge pour le saisir de son cas, ou pour demander quelque chose à une autorité, notamment pour en appeler à sa clémence ${ }^{66}$.

Dans nos documents, le sens de «pétition » doit être privilégié ${ }^{67}$. Non seulement l'un des feuillets qui nous sont parvenus est rédigé au dos d'une pétition, qui fut remployée par l'administration à cet effet (document $\mathrm{n}^{\mathrm{o}} \mathbf{I I I}$ ), mais l'existence de registres spéciaux pour consigner l'arrivée de pétitions de détenus est aussi attestée par les sources narratives. Al-Ṭabarī évoque, en l'an 249/863, une émeute de Bagdadiens qui attaquèrent des prisons et pillèrent le dīwān qiṣaṣ al-muhabbasinn situé à proximité d'un des ponts du Tigre, où était implantée la $\check{s} u r t ̦{ }^{68}$. Ce dīwān «des pétitions des prisonniers », qui avait été précédemment interprété

\footnotetext{
${ }^{64}$ E. Tyan, Histoire de l'organisation judiciaire, p. $613:$ « Le titulaire de cette fonction doit tenir registre des noms de tous les condamnés qui se trouvent dans les prisons, avec la mention de la cause de la condamnation. Il doit libérer ceux qui ont déjà purgé leur peine, et pour ceux qui sont détenus dans l'attente de l'application d'un autre châtiment, il ne doit pas tarder à l'infliger. »

${ }^{65}$ M. Tillier, Les cadis d'Iraq, p. 408-409. Voir également N. Hentati, « La prison en Occident musulman médiéval », p. 170.

${ }^{66}$ Voir M. Tillier, L'invention du cadi. La justice des musulmans, des juifs et des chrétiens aux premiers siècles de l'Islam, Publications de la Sorbonne, Paris, 2017, p. 117, 216-218.

${ }^{67} \mathrm{G}$. Khan tend à penser que les pétitions étaient surtout appelées ruq ' $a$ aux premiers siècles de l'Islam, tandis que le terme qișșa était préféré à l'époque mamelouke. G. Khan, «The Historical Development of the Structure of Medieval Arabic Petitions », Bulletin of the School of Oriental and African Studies, 53 (1990), p. 8-30, en part. p. 13, n. 19. Il ne fait néanmoins aucun doute que le terme qișsa est employé dans ce sens dès l'époque abbasside.

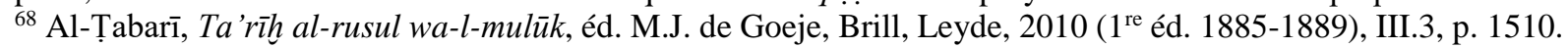


comme celui «des écrous» ${ }^{69}$, correspond plus vraisemblablement au bureau de l'administration carcérale. Al-Ṭabarī mentionne les « registres» (dafätir, sing. daftar) qui y étaient conservés et qui, lors de l'émeute, furent déchirés et jetés dans le fleuve ${ }^{70}$.

Les extraits du daftar qui nous sont parvenus de la Fusțât du début du IX ${ }^{\mathrm{e}}$ siècle ne mentionnent pas le contenu des pétitions peut-être envoyées par les détenus eux-mêmes pour plaider leur cas ${ }^{71}$. Le scribe s'est contenté d'enregistrer leur arrivée et, la plupart du temps, de préciser la nature du cas et l'identité des parties impliquées dans l'affaire. Selon toute vraisemblance, les débiteurs en appelaient à la clémence du șạhib al-šurța en expliquant qu'ils n'étaient pas en capacité de rembourser leur créance. Selon la théorie hạanafite, la mieux connue sur le sujet, un débiteur ne pouvait prouver son insolvabilité lors de son procès : son emprisonnement était nécessaire afin que la réalité de sa situation financière soit révélée par l' « épreuve » (imtiḥān) de la prison. La preuve de son insolvabilité n'était acceptable qu'après une durée d'incarcération de quelques semaines ou quelques mois, laissée à l'appréciation du juge ${ }^{72}$. On ignore néanmoins dans quelle mesure la durée d'emprisonnement était suivie et comptabilisée. Les sources juridiques et narratives laissent entendre que certains détenus étaient oubliés au fond de leur geôle ${ }^{73}$. Sous Ibn Ṭūlūn (r. 254-270/868-884), les prisonniers avaient d'ailleurs tout intérêt à se signaler à l'émir par le biais d'une pétition s'ils voulaient revoir la lumière du jour ${ }^{74}$. Le processus de pétition dont témoignent nos documents relève visiblement de la même dynamique. Une fois en prison - après quelques jours, quelques semaines ou quelques mois -, les débiteurs se rappelaient à la mémoire des autorités carcérales et entreprenaient de plaider leur cause par voie de pétition. Peut-être proposaient-ils d'apporter la preuve testimoniale de leur insolvabilité ou, comme le préconise al-Šāfi 'ī, de prêter serment qu'ils ne possédaient plus rien ${ }^{75}$. La démarche avait toutes les chances d'aboutir, puisque chaque entrée du registre est marquée d'un h̆ulliya(t)/hulliya li-ṣạhibi-hi, signifiant que le pétitionnaire a été libéré. Ces formules d'élargissement, écrites à l'aide d'un calame plus épais, signalent de manière ostensible le passage d'une rubrique à une autre; elles furent vraisemblablement apposées dans un second temps, après que la pétition correspondante eut été examinée.

Le verbe hulliya se présente comme une forme elliptique de hulliya sabīlu-hu, «il a été libéré ». L'interprétation de li-ṣăhibi-hi est moins évidente. (1) Une première solution consisterait à considérer qu'il s'agit du sujet, celui que concerne la pétition. Le pronom suffixe

\footnotetext{
${ }^{69}$ M. Tillier, « Prisons et autorités urbaines », p. 392.

${ }^{70}$ Al-Ṭabarī, Ta'rīh al-rusul wa-l-mulūk, III.3, p. 1510-1511.

${ }^{71}$ On ne peut néanmoins exclure qu'en quelques cas la pétition soit envoyée par un proche du détenu. Ainsi la pétition inédite P. Cambr. UL Inv. Michael. A 194 fut-elle écrite par une femme, dont le nom n'est pas donné, en faveur de son mari 'Ubayd Allāh b. Aḥmad qui était semble-t-il absent et incapable de rédiger lui-même la pétition, peut-être parce qu'il se trouvait alors en prison.

72 Al-Hुașșāf et al-Ğașșāṣ, Adab al-qā d̄i , p. 260-264.

${ }^{73}$ M. Tillier, « Les prisonniers dans la société », p. 197.

${ }^{74}$ Al-Balaw̄in, Sìrat Aḥmad b. Tuūlūn, éd. Muhammad Kurd 'Alī, al-Maktaba al-'arabiyya, Damas, 1939, p. 235. Voir M. Tillier, « Dans les prisons d'Ibn Ṭūlūn », Bulletin d'Études Orientales, à paraître.

${ }^{75}$ Al-Šăfi ‘̄ì, Kitāb al-umm, IV, p. 442.
} 
- $h u$ renverrait en ce cas à la dette $(\text { dayn })^{76}$. Hulliya li-ṣạhibi-hi signifierait ainsi « le débiteur a été libéré ». Cette option permettrait d'expliquer qu'en certains cas, lorsque le mot dayn n'apparaît pas, le scribe s'est contenté d'écrire hulliya(t) («il/elle a été libéré/e ») ( $\mathrm{n}^{\text {os }} \mathbf{5}, 7$ et 15). (2) Li-șạhibi-hi pourrait aussi signifier "pour son compère », c'est-à-dire son adversaire. Il conviendrait en ce cas de traduire l'expression par "libéré pour son adversaire». Cela signifierait soit (2a) que le détenu a été libéré avec l'accord du demandeur, soit (2b) qu'il l'a été pour le bénéfice de ce dernier. L'hypothèse $2 \mathrm{a}$ impliquerait que le débiteur a passé un compromis (șulh) avec son créancier, négociant soit un délai soit un moyen terme ${ }^{77}$. Néanmoins cela signifierait que le demandeur a indiqué à l'autorité judiciaire qu'il levait sa plainte. Or, nos documents évoquent des pétitions de détenus, et non de leurs adversaires. L'hypothèse 2a semble donc devoir être exclue. Demeure l'hypothèse $2 b$, qui pourrait signifier que le débiteur, libéré suite à la réception de sa pétition, se voit demander de travailler pour rembourser son adversaire. Ceci correspondrait aux recommandations du juriste égyptien alLayt b. Sa 'd : bien que minoritaires dans le fiqh et qu'al-Šāfi '̄i s'y oppose, celles-ci furent reprises à son compte par le mālikite Ibn 'Abd al-Hakam, ce qui implique qu'elles pesaient encore au début du $\mathrm{IX}^{\mathrm{e}}$ siècle dans les pratiques carcérales fusțātiennes ${ }^{78}$. Dans le cadre de cette hypothèse, la version courte hulliya(t) signifierait que la personne est libérée sans condition, soit parce que la détention n'est pas due à une dette, soit parce que celle-ci a finalement été remboursée par le prisonnier. Le seul cas détaillé $\left(\mathrm{n}^{0} 7\right)$ ne mentionne pas la raison de l'incarcération, qui pourrait ne pas être une affaire de créance : on comprendrait dès lors pourquoi la détenue est simplement «libérée », sans qu'aucune obligation ne la lie à son adversaire.

Le cas de Muhammad b. Muhrim ( $\left.{ }^{0} \mathbf{1 0}\right)$ semble confirmer cette dernière hypothèse. Selon l'entrée du registre, la libération de ce débiteur était conditionnée par la production d'un garant que l'intéressé n'était pas disposé à fournir à l'origine. Si l'on en croit la note ajoutée à la suite de cette entrée, il ne fut effectivement élargi qu'après que son neveu se fut porté garant. L'addition postérieure suggère que dans un premier temps, la pétition adressée par Muhammad b. Muhrim était demeurée inefficace : l'autorité en charge de l'affaire ou de l'application de la sentence, Faḍāla b. al-Mufaḍdal, n'acceptait sans doute pas ses arguments - peut-être la somme en jeu était-elle trop conséquente, et la famille du détenu apparaissait-elle assez aisée pour fournir un garant. C'est sans doute en raison de l'échec de sa pétition que Muhammad b. Muhrim finit par présenter un garant, ce qui assurait le remboursement de la dette. La mention simple «a été libéré » fut donc tracée par la même occasion en haut de la rubrique, impliquant que nulle obligation ne liait plus Muhammad b. Muhrim à son adversaire.

\footnotetext{
${ }^{76} \mathrm{~S}$. Hopkins relève que dans les papyrus, la préposition $l i$ - peut être introduite là où l'arabe attend plutôt un complément d'objet direct. En revanche, il ne mentionne pas un tel usage pour le sujet d'un verbe au passif. S. Hopkins, Studies in the Grammar of Early Arabic, p. 109-110. On pourrait également émettre l'hypothèse d'une contamination entre les constructions des verbes halä ( ( $^{\mathrm{re}}$ forme), qui se construit souvent avec la particule $l i$-, et halla $\left(2^{\mathrm{e}}\right.$ forme) qui est transitif. Les auteurs remercient Katia Zakharia de leur avoir suggéré cette dernière solution.

${ }^{77}$ Sur le șulh, voir M. Tillier, « Arbitrage et conciliation aux premiers siècles de l'Islam : théories, pratiques et usages sociaux », Revue des mondes musulmans et de la Méditerranée, 140 (2016), p. 37 sq.

${ }^{78}$ Sur les opinions de ces deux juristes, voir supra.
} 
Le registre, rédigé par une même main - celle du secrétaire préposé à la réception des pétitions - ne comporte pas de date hégirienne mais seulement des jours et des mois. Ces feuillets appartenaient à un daftar au début duquel l'année devait être citée, ce qui rendait inutile sa répétition. Les dates inscrites correspondent vraisemblablement au jour où chaque pétition fut enregistrée ${ }^{79}$. La proximité des dates entre les trois feuillets permet tout d'abord de conclure que nous avons affaire aux pages d'un même registre. Les documents I et II se suivaient, tandis que III ne devait être éloigné que de quelques feuillets. Ces dates permettent en outre d'évaluer la périodicité de l'arrivée des pétitions devant l'autorité carcérale, et par-là même celle des emprisonnements : le bureau reçut, à l'époque de ce registre, entre une et trois pétitions par jour, ce qui suggère que les incarcérations pour dette étaient aussi fréquentes dans cette partie de Fustāạt.

Tab. 4 : Chronologie de la réception des pétitions (chaque colonne correspond à un feuillet)

\begin{tabular}{|c|c|c|}
\hline I & II & III \\
\hline 18 șafar & 21 șafar & $\ldots r a b \bar{l}^{-} \mathrm{I}$ \\
\hline 19 șafar & 21 șafar & $\ldots r a b \bar{l}^{-} \mathrm{I}$ \\
\hline 20 șafar & 21 șafar & $9 r a b \bar{l}^{\prime} \mathrm{I}$ \\
\hline 20 șafar & ...șafar & $\ldots r a b \bar{l}^{-} \mathrm{I}$ \\
\hline ... șafar & $\begin{array}{l}24 \text { safar } \\
\ldots \text {. [safar }]\end{array}$ & $\begin{array}{l}\ldots\left[r a b \bar{l}^{\prime} \mathrm{I}\right] ? \\
\ldots\left[r a b \bar{l}^{\prime} \mathrm{I}\right] ?\end{array}$ \\
\hline
\end{tabular}

\section{CONCLUSION}

Ces extraits d'un registre carcéral sont, à notre connaissance, les premiers documents publiés qui mentionnent une série de quartiers centraux de Fusțāt. Ils confirment qu'au début du IX siècle, les noms des concessions tribales (hitaț) distribuées à l'époque de la fondation étaient toujours employés. Ces dénominations avaient entre-temps connu des modifications: le «Banū » qui précédait certains d'entre eux avait disparu à l'usage, tout comme le ahl du quartier des «ahl al-Rāya »; les appellations tribales s'étaient transformées en toponymes urbains. Ces quartiers qui, à l'origine, étaient peuplés de conquérants arabo-musulmans, accueillaient désormais des juifs et des chrétiens, signe du développement d'une mixité religieuse, sinon sociale.

Ces fragments de registre offrent surtout des informations capitales sur le fonctionnement des prisons. Ils témoignent tout d'abord de la fréquence des incarcérations pour dette, y compris pour des sommes faibles. Ils confirment, par ailleurs, que le système carcéral s'articulait autour de deux institutions principales : celle de la judicature cadiale et celle de la police ( $\check{s} u r t ̦ a)$. La

\footnotetext{
${ }^{79}$ Les pétitions qui nous sont parvenues pour cette période ne sont pas datées ; il est donc improbable que les dates du registre correspondent à celles de la rédaction des pétitions.
} 
distribution des rôles entre chacune des deux n'est pas d'une clarté parfaite dans nos documents. Le cadi apparaît sous le jour d'une autorité supérieure, susceptible d'envoyer ses ordres au chef de la police. Ce dernier assume néanmoins le rôle le plus important : il semble contrôler la prison des débiteurs - bien que les juristes considèrent qu'elle relève en principe du cadi. Le plus vraisemblable est que le chef de la police supervisait également le Bureau des pétitions des détenus (dīwān qiṣaṣ al-muhabbasīn) où était conservé le registre dont sont extraites ces pages, et où étaient examinées les pétitions des prisonniers. Il se voyait ainsi chargé de l'application des «peines »- même si l'emprisonnement d'un débiteur correspondait à une incarcération administrative et non pénale.

L'enregistrement régulier de pétitions de prisonniers, à raison d'une à trois par jour pour l'administration carcérale de la vieille ville de Fusțât, permet enfin de mieux comprendre le processus d'incarcération et de libération des débiteurs. Les sources normatives laissent généralement l'élargissement des détenus à la discrétion du cadi, s'abstenant d'évoquer les démarches administratives afférentes. Selon toute vraisemblance, le processus de pétition faisait partie d'une procédure courante, voire normée, permettant à un détenu de prouver son insolvabilité, ou tout au moins d'en convaincre l'autorité en charge de l'application des peines. Malgré la difficulté d'interprétation qu'elle soulève, la formule ḩulliya li-șāhibi-hi apposée par l'administration carcérale en tête d'une majorité de vignettes suggère qu'un grand nombre de débiteurs, déclarés insolvables, furent libérés à condition de travailler pour leur créancier. Cette mesure, encore défendue en Égypte au début du III/IX $/ \mathrm{IX}^{\mathrm{e}}$ siècle par un juriste comme Ibn 'Abd al-Ḥakam, correspondrait à un usage archaïque qui disparut du fiqh classique. 


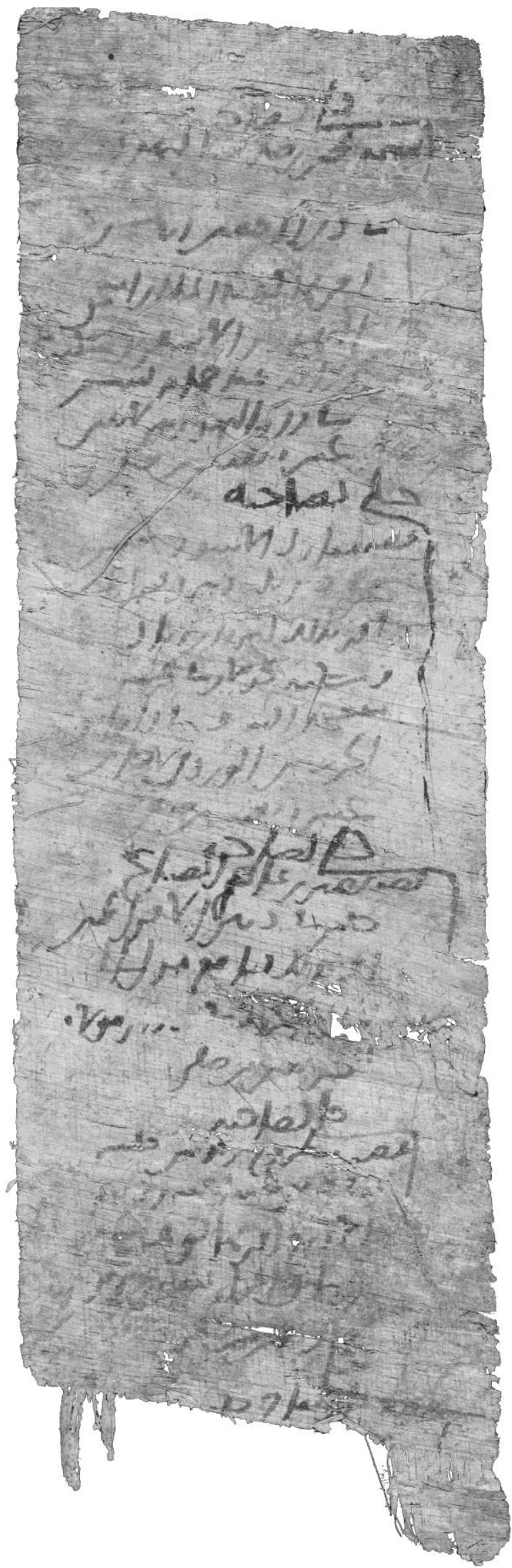

Fig. 1. P. Cambr. CUL Inv. Michael. A 156 verso (@ Cambridge University Library) 


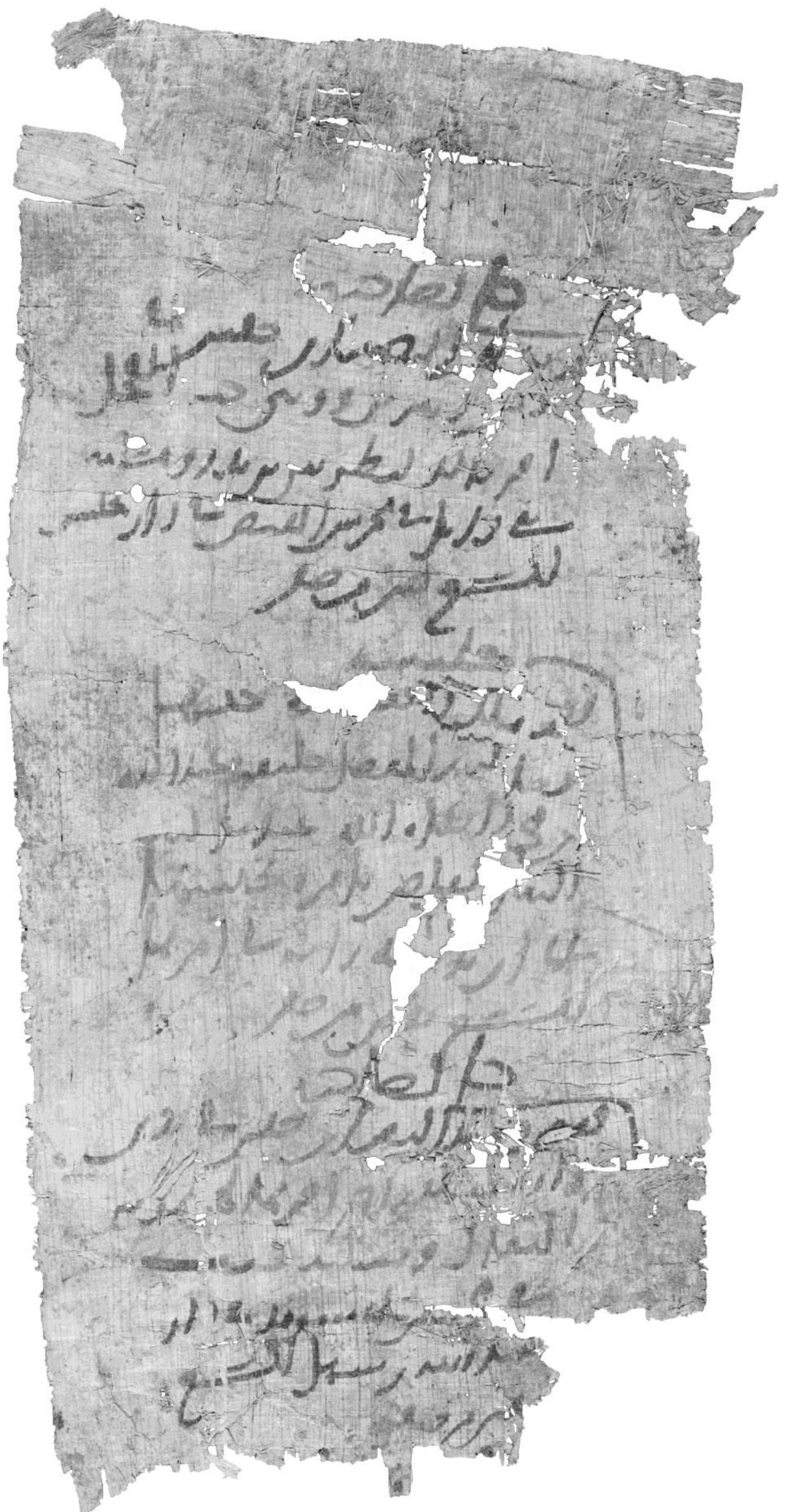

Fig. 2. P. Cambr. CUL Inv. Michael. B 515 recto (@ Cambridge University Library) 


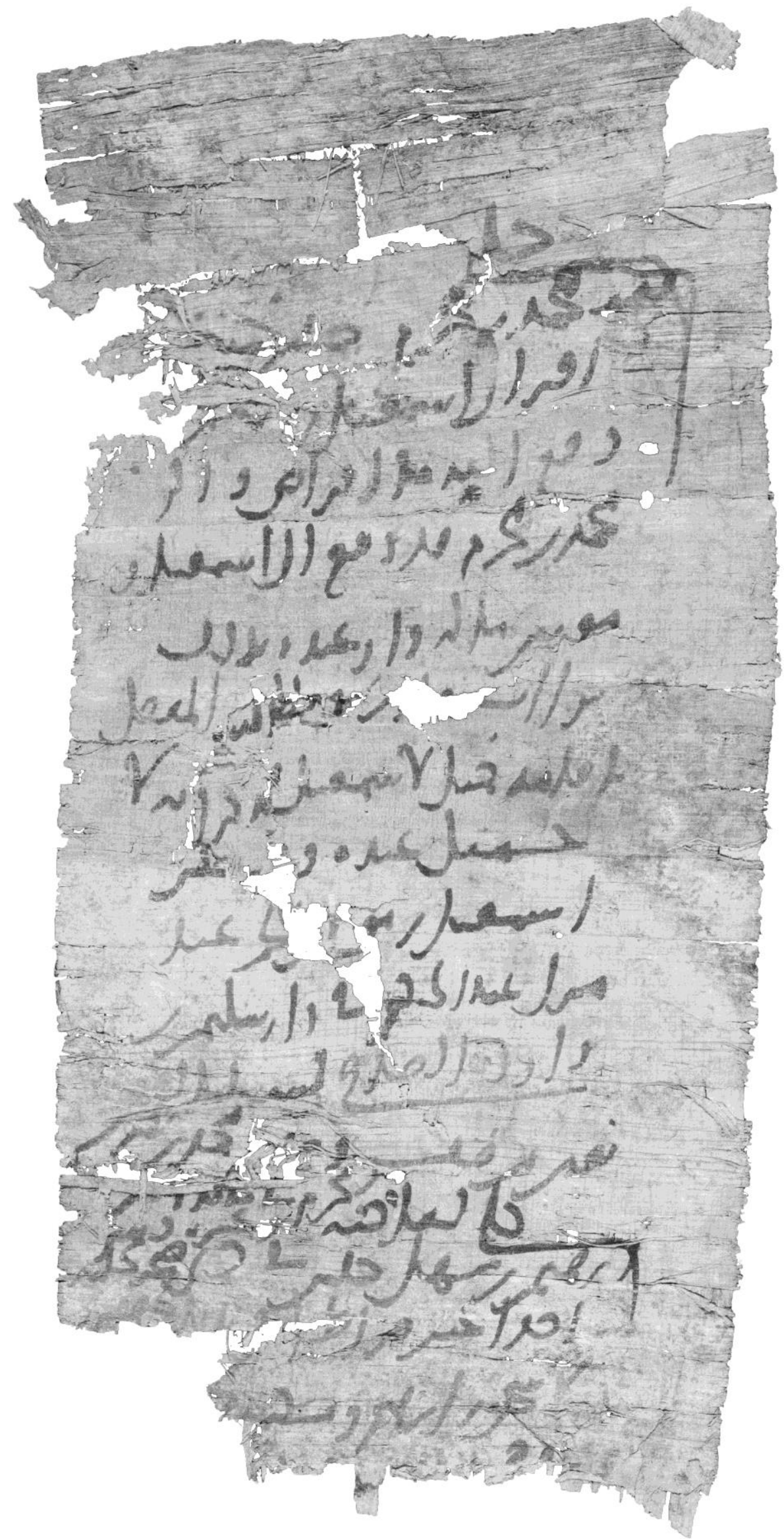

Fig. 3. P. Cambr. CUL Inv. Michael. B 515 verso (@ Cambridge University Library) 


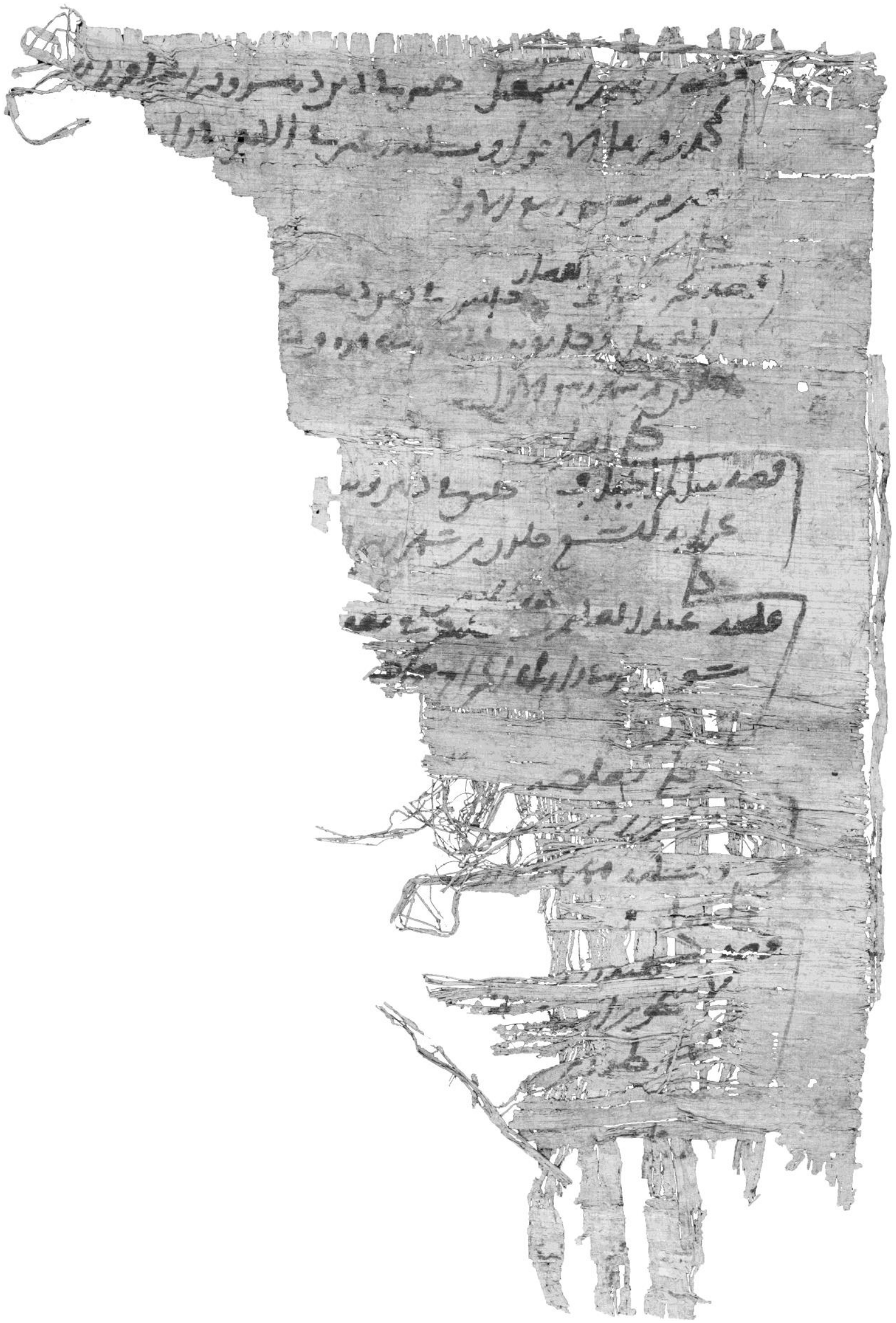

Fig. 4. P. Cambr. CUL Inv. Michael. A 1000 verso (@ Cambridge University Library) 